Florida International University FIU Digital Commons

$10-20-2011$

\title{
The Self-Perceived Effects on Faculty that Result From the Experience of Serving in a Residential College
}

Eric E. Arneson

Florida International University, earneson@fiu.edu

DOI: $10.25148 /$ etd.FI11120501

Follow this and additional works at: https://digitalcommons.fiu.edu/etd

\section{Recommended Citation}

Arneson, Eric E., "The Self-Perceived Effects on Faculty that Result From the Experience of Serving in a Residential College" (2011). FIU Electronic Theses and Dissertations. 484.

https://digitalcommons.fiu.edu/etd/484 


\section{FLORIDA INTERNATIONAL UNIVERSITY \\ Miami, Florida}

THE SELF-PERCEIVED EFFECTS ON FACULTY

THAT RESULT FROM THE EXPERIENCE OF SERVING IN A RESIDENTIAL

COLLEGE

A dissertation submitted in partial fulfillment of the

requirements for the degree of

DOCTOR OF EDUCATION

in

HIGHER EDUCATION

by

Eric E. Arneson 
To: Dean Delia C. Garcia

College of Education

This dissertation, written by Eric E. Arneson, and entitled The Self-Perceived Effects on Faculty that Result from the Experience of Serving in a Residential College, having been approved in respect to style and intellectual content, is referred to you for judgment.

We have read this dissertation and recommend that it be approved.

\begin{tabular}{r}
\hline Teresa Lucas \\
\hline Glenda Musoba \\
\hline Benjamin Baez \\
\hline Roger Geertz Gonzalez, \\
Major Professor
\end{tabular}

Date of Defense: October 20, 2011

The dissertation of Eric E. Arneson is approved.

$\begin{array}{r}\hline \begin{array}{l}\text { Dean Delia C. Garcia } \\ \text { College of Education }\end{array} \\ \hline \begin{array}{r}\text { Dean Lakshmi N. Reddi } \\ \text { University Graduate School }\end{array}\end{array}$

Florida International University, 2011 
(C) Copyright 2011 by Eric E. Arneson

All rights reserved. 


\section{DEDICATION}

I dedicate this dissertation to my wonderful wife, Tenaye, and my son Kenneth. They have spent many hours without me doing things that normally would be my responsibility so I could have time to study. To Tenaye, thank you so much for your unwavering support and even friendly demands that I press on with my work on this project. Without your gentle nudging I am not sure if I would have found the time to get through this whole process. You have had so much on your plate with your own studying and being responsible for taking care of many people, yet you took on more work, especially keeping after Kenny, so I could be successful. I am not sure how I can repay for your support, but will think of something.

To my parents, I thank you for your support as well. From constantly asking me how it was going to giving me the drive and vision in the first place. I have been very blessed with family who cares about me and wishes me to be successful. I have been more blessed than is reasonable with a great family and wonderfully supportive friends. Thanks to all of you. 


\section{ACKNOWLEDGMENTS}

I very much want to acknowledge the guidance and support I have received from the faculty I have had the pleasure to work with throughout this process. Starting with my Chair, Dr. Roger Geertz Gonzalez to my committee consisting of Dr. Glenda Musoba, Dr. Benjamin Baez and Dr. Theresa Lucas I have been fortunate to receive the training and knowledge I needed to succeed.

I also must acknowledge the patience the faculty members have had with me. I started down this journey over five years ago and I am sure there are times they were not sure I was going to get to the finish line. I appreciate the gentle nudging from Dr. Gonzalez and others reminding me to keep after it. It is often said the hardest part of the doctoral process is after you finish classes, and I can attest that is true for me. I also thank Dr. Musoba and Dr. Baez for always asking me where I was in the process when I saw them on campus; that reassurance helped me get my focus back from time to time.

From the first day I spoke to Dr. Sandiford after my first class, pestering her for questions on how to move forward in the program to outstanding classes to my defense I have found faculty that wish for me to succeed. Thanks to all of you, I appreciate you and what you do for your students.

Finally, I would be remiss not to acknowledge my supervisors. At both my last

institution and present, my supervisors have been very supportive and encouraging. I am forever grateful to all the colleagues who have helped me study or encouraged me to finish this degree. 


\section{ABSTRACT OF THE DISSERTATION \\ THE SELF-PERCEIVED EFFECTS ON FACULTY}

THAT RESULT FROM THE EXPERIENCE OF SERVING IN A RESIDENTIAL

COLLEGE

by

Eric E. Arneson

Florida International University, 2011

Miami, Florida

Professor Roger Geertz Gonzalez, Major Professor

The purpose of this phenomenological study was to examine the effects that faculty who live in residence with college students perceive result from their experience. This study examined the perspectives from current and recent residential faculty members. Data were gathered through structured interviews with current and former residential faculty who gave firsthand accounts of how they felt that experience impacted them. A pilot study had been previously conducted that enabled the researcher to modify and adjust the dissertation methodology accordingly, based upon the findings of the pilot study. The pilot study, in short, found that residential faculty members felt they gained from the experience in terms of relationships with students and other faculty while facing a few small challenges.

Literature consistently showed that faculty-student interaction is very important to the development and success of students (Astin, 1993). Research has clearly demonstrated positive outcomes that result for students; the literature review revealed this information is plentiful. There is a dearth of research, however, regarding this impact on 
the faculty members themselves. Given the importance of faculty-student interaction outside of the classroom, it is crucial to recruit faculty for these communities. Thus, more information regarding this experience will be valuable.

The study was conducted at a mid-sized private university in the Southeastern United States. The reason for this choice was the fact that this school has a 25-year history as a residential college system and utilizes $12-15$ residential faculty members yearly. The researcher conducted interviews with 13 faculty members and coded and analyzed the data, then prepared the findings of the study based on the results.

The data resulting from the study indicated that faculty perceived great benefits from serving as residential college faculty members. Perceived benefits as described by the participants included increased skill in teaching, feeling a sense of community, stronger relationships with other faculty members and students, and an increased affinity toward the university. While there were some challenges such as lack of training, politics, and loss of privacy all participants in the study felt they gained from the opportunity and would do it again in the same situation. This study enhanced the limited formal knowledge available regarding how faculty experience living in residential colleges with students. 


\section{TABLE OF CONTENTS}

\section{CHAPTER}

PAGE

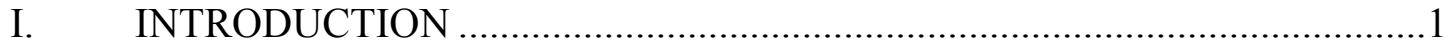



Statement of the Problem............................................................................

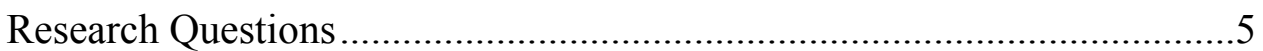



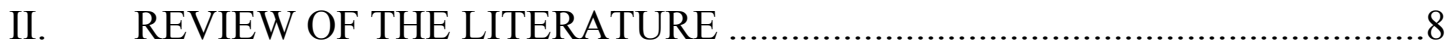

The Residential College ............................................................................

Student-Faculty Interaction....................................................................

Student-Faculty Interaction With Female Students ...................................24

Student-Faculty Interaction With Students of Color ……….....................27

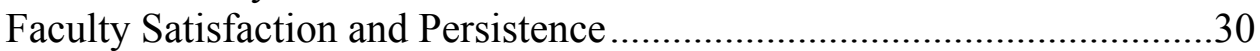

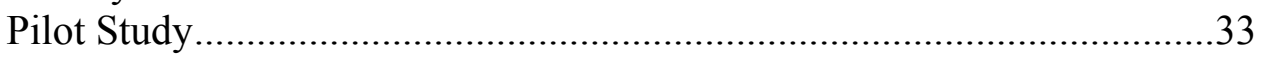

Overview of Pilot Study.....................................................................33

Qualitative Design of the Pilot Study .................................................34

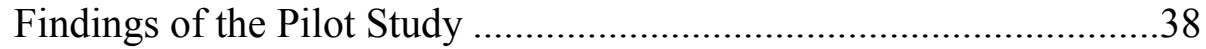



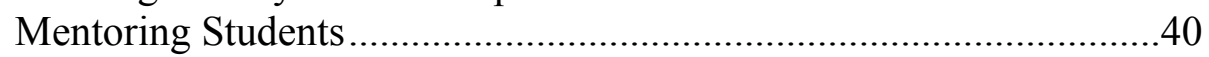



Fostering Student Independence ......................................................40

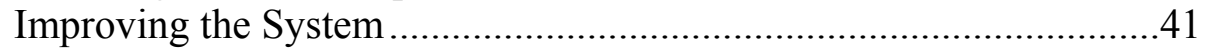



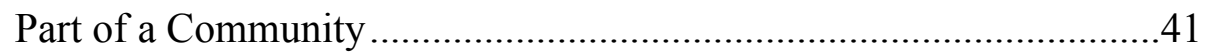

Relationships With Students ...........................................................4

Summary ....................................................... 45

III. METHODOLOGY AND RESEARCH DESIGN ……......................................48

Restatement of the Problem ...................................................................48

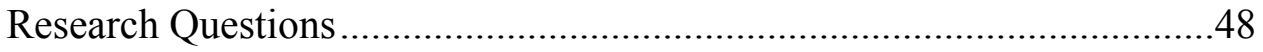

Dissertation Research Design and Procedures........................................49

Data Collection Procedure ...............................................................51

Data Analysis Procedure..................................................................5

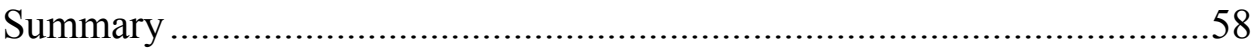

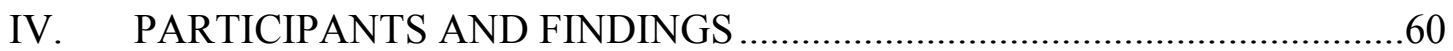

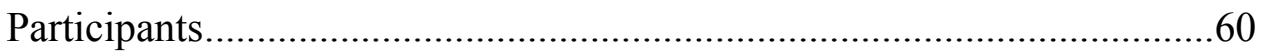

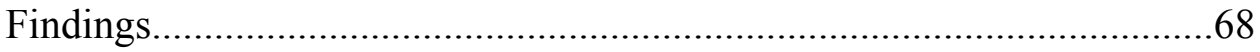

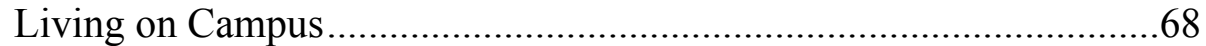

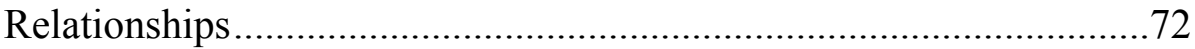

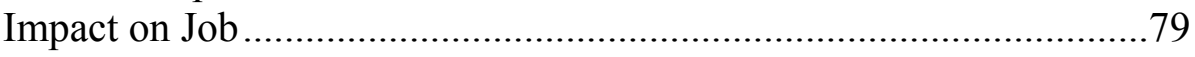




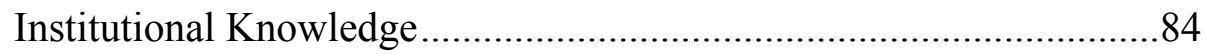





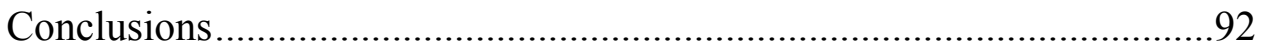

Recommendations for Practice ……………………….......................98

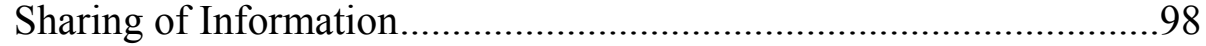

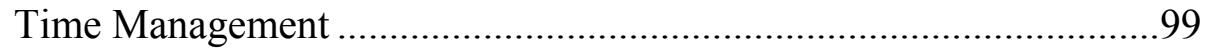

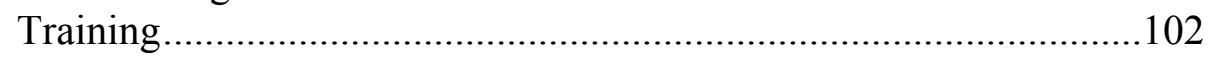

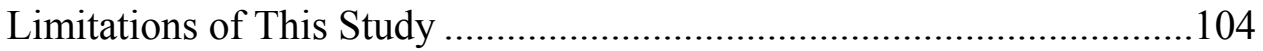

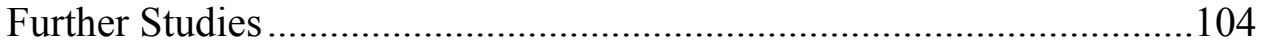

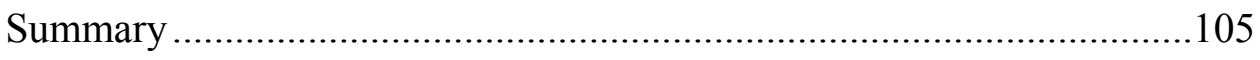

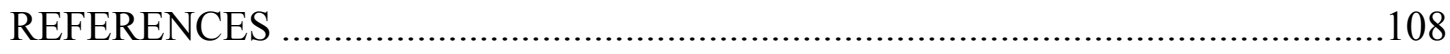








\section{CHAPTER I}

\section{INTRODUCTION}

In the 21st century American society will not continue to evolve and keep up with the ever-changing planet without an innovative and successful system of higher education (Marchese, 1997). It is incumbent upon colleges and universities to serve society by creating the best possible education for the leaders of tomorrow. For all the intricacies of higher education, none of them matter without the two elements that must be present: students and faculty. Without the success of both of these stakeholder segments, nothing else in higher education really matters. According to Hersh (1999), one way that many colleges and universities are working to create a mutually successful environment for students and faculty is the creation or reemergence of residential colleges.

Alexander (1998) noted that residential colleges had begun to appear on more campuses. This was in part to counteract the feeling of personal and intellectual isolation that many students face in today's colleges and universities. He hypothesized also that these feelings were more prevalent and more pronounced at larger research institutions. Alexander (1998) stated that after years of campus division between faculty and students, these communal educational structures have reemerged as a potentially effective means to improve the higher education experience of students and faculty (p. 13).

The key to the success of the residential college is the intentional out-ofclassroom interaction between students and faculty. On the student side of this equation, the fact that they gain significant benefit from outside-of-the-classroom interaction with faculty, is very clear from an overwhelming amount of research available on the subject (Lundberg, 2004). Astin's (1993) study on student-faculty interaction is a benchmark 
used by many describing the benefits for students. That study showed that students who interacted with faculty outside of classroom were more likely to feel a connection to their studies and their institution. In fact, students who interact with faculty are more likely to be successful in college and are more likely to persist and finish college successfully. It is important to note the other factors also play into the success of student-faculty interaction such as race and gender. For example, Lundberg (2004) explains that students of color often acknowledge less benefit from interaction with White faculty than White students do in the same situation. Sax, Bryant, and Harper (2005) also noted that while women definitely benefit from interaction with faculty overall in terms of confidence and academic achievement, the effect is a little different and surprisingly moves them more toward "traditional" gender roles. In essence, there is little doubt that student-faculty interaction is of great benefit for students; however, faculty and administrators need to be cognizant also of the potentially differing effects their interactions may have on different groups of students.

While the student impact is well documented there is clearly a dearth of knowledge regarding the impact on the faculty who give of their time and energy to live and learn with students. There are many barriers for faculty to become involved in residential colleges. Among those barriers are time, personal commitments, the tenure process, and a faculty reward structure that many times prioritizes research and publishing, which makes it very difficult for faculty to participate in this setting (Daly \& Dee, 2006). As previously mentioned, higher education does not function effectively as we know it without faculty. Faculty buy-in and participation are also crucial when it comes to attracting them to residential colleges. Given this, it is crucial to understand the 
underpinnings of faculty satisfaction and persistence. Barnes, Agago, and Coombs (1998) put forth that in the end, faculty satisfaction and persistence could be boiled down to multiple time commitments as a challenge and the feeling of community they feel with their colleagues and the university as a positive predictor of satisfaction. In a positive answer to the idea that being part of community has a positive impact on faculty, Golde (2000) found in a study of faculty who participate in intentional living-learning environments that they felt a strong sense of community with fellow faculty members also in the program and felt a strong sense of community with students. This even translated into a feeling among faculty that the experience was helpful to them in becoming better instructors.

\section{Purpose of Study}

The purpose of this study was to examine the self-perceived effects of living in a residential college. All self-reported effects were considered along with a focus on faculty satisfaction and persistence for this study. The study focused on the experience of residential faculty masters in long standing residential colleges. The study occured at a private medium-sized research university in the southeastern United States. The university has had an intentional residential college system based on the Cambridge residential college system.

The faculty masters live in residential colleges in apartments provided by the university. The apartments are physically constructed to have space designated for ongoing programming and education of students along with more private living quarters. In this system faculty masters have students in their apartments for formal and informal learning almost daily. The official role of the faculty master is to be the "intellectual 
center" of the residential college. They are charged with creating an education-focused living and learning environment where students, faculty, and staff all collaborate to foster involvement in learning.

The actual job description of the faculty master revolves around educational and social programming. The faculty master will generally oversee a team of student resident assistants (RAs) and work with them on creating a programmatic curriculum for their residents. The role is both advisory and participatory. For example, a faculty master could work with the RAs to get students to read a book by a local author, and then accompany the students on a field trip physically experiencing what was described by the author and facilitating discussion. The faculty masters also serve as a contact point for other faculty and parents who have concerns about residential students. The residential college also employs a full-time professional residence coordinator (RC) who handles the day-to-day operations of the college. In this role the RC will supervise the RAs and work with general student issues and concerns. The RC will oversee student conflict mediation and general student conduct issues. The RC in this role clears the way for the faculty to be able to focus on creating positive student relationships and programming along with the "day job" of being a full-time, generally tenured, faculty member.

\section{Statement of the Problem}

Higher education is currently in a difficult place in America. No longer does higher education get a free pass on being seen as experts at educating tomorrow's leaders. Society has become more demanding of the job colleges and universities are doing (Marchese, 1997), and accountability is more and more a part of everyday life. One factor found to be a positive predictor of student success is interaction with faculty outside of 
the classroom (Astin, 1993). Hersch (1999) suggested that an ideal setting to intentionally create student-faculty interaction is a residential college. In this setting, students and faculty are already living together in a purposeful education community, and it is logistically easier to create interaction.

While a residential college appears an excellent vehicle for creating successful student-faculty interaction, this cannot occur without dedicated faculty. As previously noted, this position requires a great deal of time and effort for already very busy faculty. While there is a substantial amount of research to validate the student experience in terms of having a positive impact on student success, there is very little research on how this interaction affects faculty (Vito, 2007). This knowledge is crucial in recruiting and retaining faculty for future residential colleges.

\section{Research Questions}

This study focused on providing the answers to the following questions:

1. What are the positive and negative self-perceived effects on faculty that result from the experience of living in a residential college with undergraduate students?

2. What are the positive and negative self-perceived effects on faculty satisfaction and persistence that result from the experience of living in a residential college with undergraduate students? 


\section{Definition of Terms}

The following is a list of key concepts utilized in this study that warrant clarification and common definition:

Faculty Master - Refers to residential college faculty members who are living with students in a residential setting and assume responsibility for the intellectual tone of the college.

Faculty Persistence - Refers to whether or not faculty continue in their position as a faculty member at their current institution of higher education (Barnes et al., 1998)

Faculty Satisfaction - Refers to the overall job satisfaction faculty self-report at their current institution. For purposes of this study, faculty satisfaction is tied to several factors including feeling of community, sense of support, and reasonable time commitments (Daly \& Dee, 2006). Faculty were asked directly to assess their job satisfaction and talk about how serving as a residential faculty member impacts their satisfaction.

Living/Learning Community - Refers to a residential community with a specific area if interest and faculty involvement with students. The main difference between this and a residential college is that the faculty do not live in the residential setting with students (Kuh \& Hu, 2001).

Oxford Style - Refers to residential colleges which are understood to have begun at Oxford University. Residential colleges are often modeled after this type of college, and the style is used as a baseline for creating residential colleges. The Oxford style is typified by small residential colleges where faculty members 
reside with the students with the intention of creating a community of scholars who are well rounded in education.

Residential Colleges - Refers to college or university residences where faculty live among students and are assigned responsibilities in creating a purposeful community of scholars and learners (Whitely, 1994).

Student-Faculty Interaction - Refers to intentional interaction faculty have with students outside of the classroom setting in an effort to help create rapport and overall student success (Astin, 1993). 


\section{CHAPTER II}

\section{REVIEW OF THE LITERATURE}

The research questions addressed by this study play an important role in helping administrators, faculty, and even students better understand the faculty-student interaction effect on faculty. More specifically, the research questions answered by this study include how faculty perceive they are affected by their experiences in the residential college setting with an additional focus on how this position affects job satisfaction and persistence as a faculty member at the university. This is a timely and pertinent area of inquiry into higher education as faculty persistence is crucial to the ongoing success of students and higher education itself (Marchese, 1997). Also, many institutions in higher education are scrambling to find ways to create intentional out-ofclassroom interactions between faculty and students (Hersh, 1999). This information will be invaluable in helping to understand the burdens and rewards for faculty stemming from this interaction and to create a body of knowledge helpful for recruiting more faculty for out-of-classroom involvement. As noted, the key research issue in this study concerns faculty-student interaction outside the classroom. In a review of the literature on the topic of faculty-student interaction, the information is plentiful, but clearly one-sided. There is a great amount of research detailing the powerful impact that out-of-class interaction has on students. However, there is significantly less information on the inverse side of the equation: What impact does spending time with students outside of the classroom have on the faculty? The setting for this research study was a residential college, which will be defined in this review. Thus, faculty interaction with students will be seen through the lens of a residential system outside of the classroom. An exhaustive 
review of the literature presented five major categories of research particularly germane to this discussion. These categories are: (a) Definition and purpose of the residential college, (b) Faculty-student interaction in general, (c) Faculty-student interaction impact on female students, (d) Faculty-student impact on students of color, and (e) Faculty persistence and satisfaction.

\section{The Residential College}

There is a long history of the residential college system as an important aspect of higher education in America and abroad. The first reported intentional residential college was founded at Merton College of Oxford University in 1264 (Ryan, 1992), over 700 years ago. The buildings of Merton were grouped around a chapel, which was a cornerstone of much of higher education at the time. The residential college was designed to move beyond the normal boundaries of teaching and education of the university and focus on the many aspects of being an educated person. Faculty lived with the students and helped shape them in terms of sobriety, chastity, and worship (Ryan, 1992). In other words, this was the beginning of the movement to educate a student as a whole person and not just as a teacher, clergy, or whatever field of vocation was being sought. It was also clear at this time in history that the "whole person" was intended to mean the spiritual and moral character naturally associated with Christian religion. The second residential college at Oxford did not follow until 1379, but it did become the first teachers college where students were taught not only to be teachers of children, but were also taught and groomed to become part of the residential college system, thus offering greater sustainability of the ideal. 
It followed naturally that when the European immigrants in America began to consider institutions of higher education that they would gravitate toward the college ideals put forth in the prestigious Oxford University. Thus, when Harvard was founded and later on Yale, William and Mary, and others, it was under a similar orientation and purpose as the Oxford residential colleges. According to Whitely (1994) students at all the early American universities lived in the "collegiate way" of not only learning a trade, but also learning the more important values of integrity and moral character. In order to achieve this ideal, students of the time lived a rigorous, inflexible schedule that included timed prayer, studying, meals, chores, and even some recreation.

As more colleges and universities began to surface in America, different philosophies began to come into play. There was a strong influence of the Germanic ideals of education, which were quite different from the traditional residential college. In this model, students were given much more academic freedom to choose courses and curricula based on interest (Klein, 2000). The Germanic system was also the first that emphasized increasing the number of students and trying to reach out to a broader spectrum of students on a greater range of subjects and vocations. Beginning in the late 1800 s, this style of education began to set the norms for higher education. In fact, this system is actually very close to the traditional model employed by most major research universities currently in the United States.

There was a major effort in the early 1900s to once again shift the focus back to residential colleges. Interestingly enough, this shift was based upon the "Yale Report," which was actually published nearly a century earlier in 1828 (Ryan, 1992). The focus of the Yale Report was curriculum. This report strongly defended the eroding curricula from 
the past that required students to study Latin, mathematics, liberal arts, and other newer subjects as seen fit by the faculty. The Yale report also made a crossover to talk about the out-of-classroom experience and describe how important it is for both students and faculty to help foster learning. This report also served as the first "modern" argument that students needed an adult figure to serve as a surrogate for the students' parents. The report further stated that there needed to be a community of trust and mutual respect between faculty and students to allow the free flow of information. The overarching goal of the report, in terms of residential colleges, according to Ryan (1992) was this:

That goal required suitable residential structures and resident faculty who know the students individually and well. The arrangements allowed not only for providing information to students through lectures-what the report called the 'furniture of the mind,' but also for the 'daily and vigorous' exercise of what is called the 'mental faculties,' on which it based its psychology. (p. 2)

The aforementioned shift in the concept of education, utilizing the Yale Report, was spearheaded by then University of Princeton President, Woodrow Wilson. This quote by the former president serves as an excellent summation of his philosophy: "Princeton is not a place where a lad finds a profession, but a place where he finds himself." He continued, "The ideal college should be a community, a place of close, natural intimate association, not only of the young men... but also of young men and older men...of teachers with pupils, outside of the classroom as well as inside it” (Pasque, 2005, p. 250). It is obvious from this statement and the preceding report that many academics and some members of the public were beginning to lose faith and comfort in the Germanic system of more students and more student autonomy. This system was seen by many as an 
abdication of the responsibility of the university to create well-rounded young men and citizens. Following the words of President Wilson, Yale President, Edward S. Harkness proposed a complete restructuring of their educational system to incorporate a full-scale residential college in 1926 (Whitely, 1994). There were some other colleges and universities that also moved to a residential college system, but most still continued to utilize the Germanic model of education.

This history now leads us to the present. There is once again a rise in interest in residential colleges. Much of the reasoning is along the same lines as the Yale report and earlier ideas. There is concern on the part of many academics that our current educational system is far too anonymous and impersonal and fails at the job of helping students find something in themselves beyond a career.

With a historical understanding of intentional student-faculty interaction in the form of residential colleges, it is now time to focus on the expressed purpose of said colleges. Hersh (1999) notes that the residential liberal arts college is still the best model of undergraduate education in America. One reason, he notes for this assertion, focuses on the impersonal nature of major research institutions, or even medium-sized institutions. Cox and Orehovec (2007) also supports the notion that at larger, research-oriented schools students have far fewer opportunities to interact with faculty and feel less connected to their venue of higher education. Hersh (1999) surmises that parents are loathe to send their students to schools a long way from their homes where their children are going to live in towers with other students, sometimes 2,000 or more in one building. They feel that their children are going to get lost in the crowd and not receive the personal attention and care that they need to succeed. They are also concerned about the 
large classroom sizes, sometimes in the thousands, with one teacher and perhaps even just a television screen. Parents have also become leery of undergraduate students not really even being wanted at prestigious schools, but often serve the purpose of funding the perceived more important graduate education. The following passage from Hersh (1999) greatly exemplifies many people's perceptions of the current state of higher education:

An undergraduate at an American research university can receive an education as good as or better than anything available anywhere in the world, but that is not the normative experience. Again and again, universities are guilty of an advertising practice they would condemn in the commercial world. Recruitment materials display proudly the world famous professors, the splendid facilities and the ground-breaking research that goes on within them, but thousands of students graduate without ever seeing the world famous professors or tasting genuine research. (p. 176)

Thus, a primary purpose and rationale for residential colleges is a good faith effort to gain back the trust of the students and parents demonstrating that colleges and universities do not abdicate responsibility for the growth and development of students. People watch our political, social, and even educational leaders continuing to fabricate lies, telling them one thing and doing another. Higher education can no longer survive on the "just trust me" philosophy of taking care of students. It is interesting how this philosophy returns all the way back to the Yale Report in 1828, where parents are looking for the university to, at least in some way, supplement the parental role. According to 
Hersh (1999) colleges and universities are receiving more fragile students. The issues and baggage students are bringing with them to college seem to continue to rise exponentially. Students are now dealing with more issues than ever ranging from depression, suicide, sexual orientation, alcohol and drug abuse, parental divorce, mental disabilities, and much more. In this setting it certainly seems logical that students and parents might feel more at ease with the comforting notion of the residential college where faculty, staff, and other students will all be theoretically engaged in living and learning together.

Boyer (1999) describes another purpose of the residential college system, that of integrated learning. He discussed the fact that in this setting, students are far more likely to be involved in co-curricular activities. Since the greatest amount of time spent by a student is out of class, by far, it just makes logical sense that if there was a way to marry the out-of-class activity with the in-class activity and faculty, the opportunity for learning is nearly limitless. Students can learn and share a great amount of information in afterhours activities like debates, team-building activities, student government, and myriad other opportunities that await them in a residential college. Since the college is also occupied and led by live-in faculty and staff, they are naturally the "adult figures" students will turn to for leadership and mentorship, even in the seemingly unrelated cocurricular activities.

In an effort to facilitate the learning just described, Boyer (1999) created an outline for how this ideal residential college would run. In fact, he received a major grant to work with Carson-Newman College to actually create this system. In his system each residential college picks a group of five individuals to facilitate all program and 
educational outreach in the college. This team of "residential fellows" was composed of one faculty member, one administrator, the residence coordinator, and two students. In this group all five fellows have the same authority for decision making and planning of programmatic outreach. In Boyer's assessment after 10 semesters it appears the program is still working well and has created a better sense of community between the faculty, students, and staff.

A recent study by Edwards and McKelfresh (2002) provides an educational look into a couple of other purposes of a residential college. The authors surveyed students at an institution where they could choose to be part of a living/learning residential community or a more traditional residence hall. By looking at persistence at the university and in the residence halls and at the academic impact of participating in the residential program, Edwards and McKelfresh shed light on the correlation between student success and faculty involvement. Their findings were quite clear in that there was a significant impact on the students who had chosen the residential living/learning center. The authors found that students in the living/learning center had more than a $10 \%$ higher rate of retention to sophomore year and also had higher GPAs.

Obviously, in terms of purpose of the residential college, the primary opportunity for student learning occurs with formal and informal interactions with faculty. Astin (1993) stated that students who interact frequently with faculty are more likely to be satisfied with their college experience, and even more important, they are more likely to persist and succeed in college in general. Interestingly, according to Astin's studies, student satisfaction in many areas increases in conjunction with regular interaction with faculty. This satisfaction list includes student friendships, choice in curriculum, 
intellectual environment, and even the administration and running of the college or university. On the flip side, Pascarella and Terenzini (1991) show that faculty also have greater overall satisfaction from their interaction with students. Their research showed that faculty who had significant student interaction outside the classroom had a greater overall satisfaction in their work. The authors indicate that faculty members felt they grew personally and professionally from student interaction. Faculty members also felt a tremendous sense of accomplishment when they feel they had had the opportunity to mentor or impact a developing student. While some academics my not want to admit it, the fact that they had so much contact with students, especially in a residential college setting, also created a near limitless amount of possibilities in terms research and studying human interaction and behavior.

A more recent study by Astin (1999) did a nice job of summing up the rationale for residential colleges. This study looked at faculty perceptions of the institutions and purpose. He found that colleges and universities with residential colleges were perceived as more student friendly. Not coincidentally, major research institutions tend to score the lowest on student orientation. In general, the study showed that the larger the size of the school, the lower the score for student orientation. For this very reason many larger schools have recently developed or are in the process of creating residential colleges to help break down the size barrier and create smaller living/learning groups where students will have a better chance to feel part of a community and therefore, have a better chance at success on the collegiate level. 


\section{Student-Faculty Interaction}

The next focus of the literature review is to examine the general impact noted from the interactions between faculty and students. This information is seen almost exclusively from the student side of impact. Overall, the studies have shown consistently that faculty-student interaction has had a positive impact on students. For example, according to Sax et al. (2005) student-faculty interaction has been positively associated with a myriad of desired outcomes. Some examples of these outcomes are students' perception of their leadership abilities, social and academic self confidence, an enhanced sense of emotional well-being, increased commitment to social responsibility, and persistence toward attaining a bachelor's degree or beyond.

These findings were consistent with research done with regards to faculty-student interaction. To better illustrate this point two important and more recent studies will now be examined extensively. Kuh and $\mathrm{Hu}$ (2001) presented a study discussing effects on student-faculty interaction on students during the 1990s. The purpose of the study was to further examine the impact on students from interaction with faculty and to ascertain whether or not the changing types of students (and faculty for that matter) had caused a differing of impact for students who have interactions with faculty members.

The Kuh and $\mathrm{Hu}((2001)$ article began with a very brief literature review discussing the impact of student-faculty interaction prior to their study. It was discussed that, in general, previous studies showed that more contact between students and faculty both inside and outside of the classroom tended to give students greater satisfaction with their educational experience and they tended to be more likely to be academically successful. It was also pointed out that colleges and universities are seeing the need for 
promoting student-faculty interaction, and many of them are offering incentive programs for faculty members to become engaged with students outside the classroom. The authors were quick to point out; however, that social interaction in itself was not enough to greatly influence student behavior and success. Social involvement was helpful for students, but to have the greatest impact it was important for the interaction to have some intellectual component. This component could be in the form of discussion about career or graduate school or just a purposeful interaction around some educational topic.

Kuh and $\mathrm{Hu}$ (2001) utilized a quantitative research method to gather the resultant data. The survey instrument used was the College Student Experiences Questionnaire (CSEQ). The CSEQ is a popular instrument used to gather information about student characteristics. For example, nominal data such as age, gender, race, and others were collected and linked to students' experiences in different areas such as time devoted to certain activities, perception of the educational environment, and progress made toward a variety of desirable outcomes. The CSEQ is well known and is considered to have moderate to high potential to assess student behavior as linked to outcomes (Kuh \& Hu, 2001). The survey instrument is a self report; however, the authors claim that since the questions are phrased unambiguously the responses will be thoughtful and valid. There were a couple of potential problems with this survey. The survey was over eight pages long and takes a significant amount of time; thus a potential confounding variable in what type of student is willing to take the time fill out the survey. Another potential issue is cost. To facilitate a web-based survey, there is a $\$ 495$ fee plus a $\$ 2.25$ fee for each student who completes the survey. Thus, some researchers will not be able to utilize this survey simply because of the costs associated with it. 
The sample used for the study (Kuh \& $\mathrm{Hu}, 2001)$ was rather ambitious. There was an $\mathrm{N}=5,409$ students from 126 different colleges and universities which approximates $10 \%$ of full-time enrolled (FTE) students at these institutions. The types of institutions included research universities, doctoral universities, comprehensive colleges and universities, selective liberal arts colleges and general liberal arts colleges.

The finding of the study (Kuh \& $\mathrm{Hu}, 2001)$ validated and clarified previous research. First, in terms of the amount of student faculty interaction, there was a progression. As one might expect, the amount of contact between students and faculty increases as students progressed through college. Students are more confident to seek out faculty as they gain more experience, and faculty are more likely to make themselves available for juniors and seniors. Secondly, it was shown that students who make more effort in other areas of their college experience were more likely to have higher levels of satisfaction with their amount of interaction with faculty. The third finding reported was that there is a difference in the amount of student-faculty interaction at different types of institutions. Not surprisingly, small colleges had the greatest amount of interaction, and large research institutions had the lowest amount of interaction. The quality of interaction also followed the exact same pattern of greater interaction for the smaller type of educational settings. The last finding was that the effects of student-faculty interactions were conditional. Students who were the most academically prepared and spent more time on coursework and intellectual pursuit reported great amounts of time and benefits from interaction with faculty.

As noted earlier, this study (Kuh \& Hu, 2001) helped to validate earlier studies. It showed that generally students gained from their interaction with faculty both in and out 
of class. However, socially oriented contact did not help very much in moving students toward desired outcomes; an intellectual component is important. In critiquing the study, the methodology was strong and the sample size is impressive. To obtain responses from over 5,000 students and 126 varying types of institutions should provide some generalizability. Unfortunately, many diverse types of institutions (historically Black colleges, women's colleges, Hispanic-serving colleges, tribal colleges, community colleges) were not mentioned so it is uncertain if some groups of students are unaccounted for. It would also be fair to point out that the literature review was very limited. It consisted of fewer than two pages and generally assumed the readers understand the positive impact made by student-faculty interaction. If I were to improve upon this study, I would have done a more thorough review of the literature. The study is potentially limiting because of the missing diversity factors and could have been stronger with a more diverse sample. It would be beneficial to attempt to obtain data for the diverse institutions discussed earlier to get more generalizable data.

A second recent study on general impact on college students was presented by Cox and Orehovec (2007). This study focused on student-faculty interaction, but specifically in a residential college setting. This study provided a link between facultystudent interaction and the usefulness of a residential college in creating these intentional relationships. The article began with an overview of the literature. The authors discussed similar finding regarding positive impact on students resulting from interaction with faculty members. The authors set up their study by discussing the frequency of interactions (which they feel is quite low) and by what process these interactions take place. The study was guided by two research questions: (a) What is the nature of student- 
faculty interactions outside the classroom? and (b) What conditions foster or inhibit these interactions? The literature review is completed by defining residential colleges (or residential learning communities) and giving a brief historical overview.

The research study was done qualitatively. Cox and Orehovec (2007) pointed out that most student-faculty interaction studies were quantitative and specified the aforementioned CSEQ as a commonly used tool. The authors decided to supplement current research with rich qualitative data from one currently working residential college. The study had a three-pronged approach. First, the authors were participant-observers in the activities of the residential college for 12 months. They noted and coded behavior at major functions such as "teas" where students and faculty interacted. They also held four focus groups of five individuals each. The focus groups were created from students very involved in the residential college in order to get the perspective from students more likely to be involved with faculty. Finally, from the focus groups certain individuals were identified for a one on one interview. The students chosen for interviews presented a mix of positive and constructive thoughts on student-faculty interaction in the residential college. It should be noted that the researchers were graduate assistants employed by the residential college.

The data were analyzed and coded by content and context of student-faculty interactions. The result was the creation of five general types of interactions. These interactions are fluid and are, in descending order, disengagement, incidental contact, functional interaction, personal interaction, and mentoring (Cox and Orehovec, 2007).

The most common form of student-faculty interaction was, unfortunately, disengagement. In this type of interaction student and faculty choose not to engage with 
each other outside of the classroom. This was evidenced both by students and by faculty who chose not to attend residential college functions, and when they did, simply sat to the side and interacted with other faculty members. What is somewhat surprising about disengagement being the predominant type of interaction is the fact that this study took place in an intentionally designed residential college. The implications for "normal" college settings are disheartening. The second most frequently observed type of studentfaculty interaction was incidental contact. This is basically contact that was unintentional between students and faculty. An example of this was students and faculty passing by each other in the college and exchanging a hello or a faculty member commenting on a student's attire. Interestingly, even in this haphazard experience students were comforted by the fact that the faculty were around.

The third most common type of interaction observed was functional interaction. These interactions occurred for specific, institutionally related purposes. The most common type of functional interaction occured when a student visited a faculty member's office for course information or advising. Faculty and students working together on a course project would also be a good example of a functional interaction. Functional interaction can also lead to the fourth most common type of student-faculty interaction, personal interaction. In personal interaction, there is purposeful contact between students and faculty. What distinguishes this from functional interaction is that there is a personal interest which creates the interaction. An example of this would be a student and faculty member sharing an interest in a cause. They could spend time and share thoughts and experiences on the topic. Students generally felt that this humanized faculty, and they viewed faculty more as people and less of a threat. 
The final and least frequent type of student-faculty interaction was mentoring. Mentoring is difficult to define but it is generally seen as a combination of helping students with career planning, emotional and psychosocial support, and some type of role modeling (Cox \& Orehovec, 2007). Thus mentoring is defined in terms of relationships, not programs claiming to be mentoring. Unfortunately, over the course of 12 months of observation in the residential college, the researchers observed only one mentoring relationship. Interestingly, in discussion faculty members asserted that they had many mentoring relationships while students in focus groups in the same residential college felt this was a very rare phenomenon.

That study provided some very interesting and useful information. However, in critiquing the study the research methods have to be somewhat questioned. The Kuh and Hu study (2001) discussed earlier utilized 126 different institutions. While this was a qualitative study it focused on just one residence hall on one campus. So, while the data were very rich, it would be a stretch to say there was much generalizability. This was also clearly a convenience sample. The researchers studied the very students they were being paid to work and live with on a daily basis. This would give a very deep understanding of the data, but also could influence behavior of students. The literature review, on the other hand, was very well researched and also provided a definition and a historical overview of residential colleges, which was very helpful to the reader. In order to improve this study a researcher from outside of this residential college could have been utilized. This would have helped alleviate any concerns that the researchers were biased about what they concluded or were too immersed in the program to see from a perspective outside of the community. 
The results shown were important. This study showed that while most students do not take advantage of the opportunity to interact with faculty, the opportunity is there. The results also show that the residential college is a setting in which interaction; even at lower levels is more likely to take place than anywhere else outside of the classroom. Also, more beneficial personal interaction and mentoring can evolve from the incidental contact which is far more likely in a residential college setting than most other venues. Even in a worst-case scenario where students and faculty do not interact very often, this study shows students have a feeling of comfort simply knowing that there are faculty members in the community.

\section{Student-Faculty Interaction with Female Students}

While the research clearly demonstrated the overall positive impact on students resulting from out-of-class interaction with faculty, the results can vary based on diversity factors. The next focus of the literature review examines the impact of facultystudent interaction on women. A recent study by Sax et al. (2005) examined studentfaculty interaction through the lens of impact by student gender. More specifically the study examined whether or not the impact of student-faculty interaction on a range of outcomes differed from women to men. The authors introduced findings consistent with previous articles in the literature review. However, they also presented studies more focused on gender in her review. While still acknowledging the positive impact interaction with faculty has on students, Sax et al. (2005) point to some research which shows differing impact on women than men. An example of this would be that women's self-confidence in mathematical ability actually declined with more interaction with 
faculty on that subject. Thus, the purpose of Sax et al. study was to see how the impact of student-faculty interaction was different for women than for men.

The data were pulled from a large, longitudinal study done by UCLA in the mid to late 1990s. The sample size was $\mathrm{N}=17,637$ students from 206 different 4-year colleges and universities. The sample comprised 10,901 women and 6,736 men. The researchers computed cross tabulations of student-faculty interaction separately by gender. These categories were then compared to a list of 42 different dependent variables to ascertain scores for men and women separately in each area.

The results of the study showed that while there was clearly an overall benefit for students who interacted with faculty outside the classroom, there were differences on how certain types of interactions affected women and men. Overall, women indicated that faculty provided them with more intellectual challenge than what the male students reported. Both men and women indicated that interaction with faculty led to higher levels of political engagement, critical thinking skills, and interest in higher education (Sax et al., 2005).

While this study confirms many of benefits as discussed in earlier studies, it does also point to some differences in student-faculty interaction for women and men. One major finding was that women reported more time spent interacting with faculty and had a higher perception of how that benefited them. On the other hand, the men who did spend time with faculty outside of the classroom reported to feeling an increase in their status and a competitive edge with their classmates. It was also found then men gained more from women in terms of social issues when interacting with family. Men were more 
likely to change their views on social concerns such as cultural awareness, gender equity, political engagement, and competitiveness.

There were some negative consequences for women when interacting with faculty in this study. For example, women who did not feel the faculty members treated them seriously noted a higher sense of feeling overwhelmed then men. Men also reported an increased drive to succeed when challenging the ideas of a professor while women generally found their relationship with faculty to decline after such interactions. Interestingly, working on research with faculty produced different impacts on women and men. Men reported to have more egalitarian views after working with faculty, while women reported have moved to more traditional gender roles.

This study provided some new and interesting information which will be useful for faculty and administrators. Again, this study supported the notion that in general student-faculty interaction is positive. However, it did point out that men and women have some differing responses to different types of interactions. Faculty members need to understand that students perceive interactions differently, and it is always wise to work to understand how each individual student is responding to the interaction and not assume men and women perceive the same things. Overall, the study was clearly laid out. It started with a thorough review of the literature and the introduction of some less publicized students regarding gender. While the researchers did not interact with students personally, they drew data from a very large sample and reputable source. This study should be very useful in helping faculty better understand that women and men may have differing needs and perceptions in interacting with them. A way to improve this study would have been to conduct some original qualitative research. As Shank (2002) pointed 
out; the only way to obtain thick, detailed information is via qualitative research. I would suggest qualitative research with female students to triangulate the finding of this study, but also to go to the next step and find out why women were affected in the manner they were.

\section{Student-Faculty Interaction With Students of Color}

The final study of this literature review is presented by Lundberg (2004). This study discusses the frequency and quality of student-faculty interaction and analyzes it by race/ethnicity. The literature review comprises familiar studies showing that interaction with faculty outside of the classroom was generally a benefit to all students. However, the author also introduced a few studies delineating those interactions by race and ethnicity. For example, she pointed out that many students feel more comfortable interacting with faculty of their own race or ethnicity, and they were much more likely to share personal information with faculty of the same race or ethnicity. Lundberg (2204) also points out that White students generally reported the greatest satisfaction with their interactions with faculty and were generally more comfortable with them. Also, African American and Latino students reported more negative perceptions of campus climate and thus more negative responses to interaction with faculty than White students.

The research method for this study was quantitative. The research instrument was the College Student Experiences Questionnaire (CSEQ), as in some of the other studies presented. The sample consisted of 4,501 undergraduate students who took the questionnaire between 1998 and 2003 from doctoral, master's, and bachelor's level colleges and universities. The data were drawn from over 20,000 students and 
oversampled to produce significant numbers of students from each different racial or ethnic group studied.

The results verified previous findings that quality relationships with faculty had a positive impact on all groups of students. Also, quality of the relationship was found to be a predictor of learning in all racial and ethnic groups. The study also reaffirmed that the higher the amount of interaction with faculty members the higher the amount of learning for the student as well as the more frequently faculty contact resulted in higher student effort.

This report showed some differences as well. African Americans and Native Americans had the highest amount of interaction with faculty. However, they also reported the lowest perceptions of their relationship with faculty members. Conversely, White and Asian students had the lowest amount of contact with faculty, but had a higher perception of their relationship with them. An interesting note potentially related to the study showed that African American students are the most active group on campus but report fewer benefits from this involvement. African American students also reported very positive impact from faculty interaction when it was positive or encouraging. On the other hand, negative feedback from faculty had a much more substantial negative impact on African American students than on White students.

Lundberg's (2004) study reinforced the powerful impact faculty has on students. Again, students were generally positively impacted by out-of-class interaction with faculty. The study also pointed out that students from different backgrounds have differing needs and perceptions. While students of color can gained greatly from interaction with faculty, they are also leery of stereotyping and lowered expectations they 
have seen. While faculty and administrators may not feel comfortable with the idea, students seem to be more comfortable with faculty who share their own racial or ethnic background. However, since this is not always possible, quality relationships with high expectations also have a very positive impact on students of color in particular, but all students. This study was well researched and used a known and reliable survey instrument. However, the author did not state who actually collected the data and from where it originated. Also, the questionnaires were distributed to a mostly White population, so other types of colleges and universities do not seem to be included in this research. To improve the research, I feel it would be important to broaden the spectrum of students who received the survey. It would be important to know, for example, how Native American students at a tribal college were impacted by faculty-student interaction versus Native American students at a predominately White institution.

In general, this literature review supports the idea that students gain from their interaction with faculty. Student-faculty interactions have shown to produce positive outcomes for students such as better grades, higher retention rates, stronger selfconfidence, and many other positive results. It has also been illustrated that not all students are impacted in the same way by the same interactions with faculty. Therefore it is incumbent on faculty and administrators to treat each student as an individual and hold them to high expectations. Nowhere on campus is it more likely to create the out-of-class interaction than in a residential college. In this setting students and faculty live and learn together and at the very least, many more opportunities exist for intentional and meaningful interactions to occur. The research presented for this current study 
compliments the very limited amount of research available regarding how students benefit from interactions with faculty and the differing effects felt by students of color.

\section{Faculty Satisfaction and Persistence}

Clearly the demands of being a college or university professor are significant. The hours can be tiring, the administration and students demanding of their time, and many faculty are still strongly encouraged to focus on research while meeting the other burdens placed upon them (Daly \& Dee, 2006). While there is a divergence of literature to be found on the topic of faculty satisfaction and persistence, the results seem to remain fairly consistent.

Barnes et al. (1998) found the when all the aspects of their research was boiled down, two major themes arrived. The two prevalent themes they found were that faculty satisfaction and persistence could be predicted by multiple and possibly conflicting time commitments and the sense of community they felt existed in their own departments and the university as a whole. Their study was a stratified, random sample of faculty from 306 institutions of higher education and encompassed 3,070 faculty members. The institutions represented all types of Carnegie classifications: Research Universities I and II, Doctoral Granting Universities I and II, Comprehensive Universities I and II, Liberal Arts Colleges I and II, and Two-Year Colleges (Vito, 2007). The faculty members' survey had to fit the parameter that they did not intend to retire in the next 5 years to avoid potential confounding variables related to retirement. As indicated earlier the sense of community felt by the faculty members was the single most important issue in faculty deciding to stay in their positions. However, time management issues were also a key factor. Other important factors associated with faculty wanting to stay in their positions 
found by Barnes et al. (1998) were faculty rewards systems, institutional reputation, and interest in their discipline. It is interesting to note that interaction with students outside of the classroom or even relationships with students was not noted as a significant factor of faculty satisfaction and retention in this study. One likely reason for this finding is that, unfortunately, out-of-class interaction does not happen with great frequency in higher education (Cox \& Orehovec, 2007).

In another recent and helpful study Lindholm (2003) presented the idea of faculty satisfactions and retention in terms of perceived organizational fit. Her study was a qualitative set of interviews with 36 full-time tenure track faculty at a large public research university. The 36 faculty represented a variety of disciplines and fields in higher education. Lindholm (2003) found that most faculty have a difficult time describing their fit with a university as a whole and tended to focus more on their specific department. While the researcher said it was difficult to get faculty to corroborate each other's perspective (most felt they held a unique perspective) she was able to identify some themes of what they found important to their satisfaction and/or persistence. Faculty felt the need to "establish a sense of space in the university that is distinctively their own-neither too distant from nor too connected with their department and institutional colleagues and where they feel comfortable, respected, and appreciated for genuinely being themselves." (p. 143).

Fortunately, Lindholm (2003) did find that most faculty interviewed in her study did feel a good fit with their department. Most faculty felt that the crucial collective support to nurture their support and growth was available. For this particular study the faculty felt that their ability to be successful in their own discipline was enhanced and 
supported by the institution. Again, this study was very helpful in corroborating the important issues at play when attempting to ascertain faculty satisfaction and persistence. However, the idea of faculty-student interaction did not seem to be a major factor that was uncovered in this research.

Golde (2000) did actually present a study which linked out-of-classroom interactions with students to faculty satisfaction. He found that faculty did find satisfaction in residential communities specifically. The benefits as seen by faculty in this study were working with colleagues in student affairs and faculty from other disciplines. Some faculty also reported that the increased contact and interaction with students had helped them better learn the students needs and thus helped them become better teachers inside the classroom. Johnsrud (2002) found similar benefits described by faculty in an examination of multiple studies. She concluded that reducing stress was a crucial component to faculty satisfaction and persistence. She further noted that stress for faculty was greatly reduced by promoting positive relationships with administrators and encouraging faculty-student interaction. Thus, the residential college is an ideal setting for intentionally creating these stress reducers for faculty.

Philpott and Strange (2003) presented a research article relating directly to the benefits and challenges of serving a residential college system. They interviewed two faculty members, two university administrators, and two student affairs professionals. They found that their satisfaction was positively affected because they were able to learn much more about their students and thus had more appreciation for them as people. More important, they felt this experience made the better at teaching as a result of increased knowledge of students. A slightly negative impact on satisfaction for the faculty in this 
study was their perception of "politics" and bureaucracy that sometimes made it difficult to achieve what they wished to do.

\section{Pilot Study}

\section{Overview of Pilot Study}

I have completed a pilot study for this research. The pilot study was completed in the summer of 2007. The study was the capstone of my qualitative research course and reviewed by the professor. My dissertation methodology was modified and adjusted accordingly based upon the findings of this pilot study. For example, the interview questions were adjusted to add more probing and follow up questions which created more detailed data in the actual dissertation.

The purpose of this study was to gain deeper understanding on why faculty members decide to alter their lives to the point of giving up their homes temporarily and moving on campus to live with students. There are obviously positive and challenging aspects to this lifestyle and both sides were examined thoroughly. This was an especially important topic given the fact that many institutions of higher education are moving toward creating residential colleges (Klein, 2000) and thus will need to recruit faculty members to participate in the program. Having a good understanding of how residential faculty feel about their experience can only strengthen the knowledge base administrators need when working to secure quality live-in faculty members. Given this goal, my stated research question was as follows: "What are the self-perceived positive and negative outcomes for a faculty member who serves as residential faculty master living with undergraduate college students?" 
I selected this topic for several different reasons. First, I have professional experience in residential life and have watched with great interest as more emphasis was placed on residential colleges in student affairs graduate programs and have seen many schools move toward creating residential colleges, or at least faculty interaction programs. Some of my professional experience includes direct involvement in residential colleges. This gives me some good insight into the concept. Miles and Huberman (1994) warn, however, that is it very important to acknowledge potential bias in a study like this. While I can see the pros and cons of the residential college system, the fact that I worked within this framework has potential to color my interpretation. In order to avoid this potential bias, I member-checked the transcripts with the subjects and also compared them to the literature review. The participants in the study did not show concern with any of the transcripts.

All of the faculty members who worked in the residential colleges at this university still teach a full load and maintain all of their academic responsibilities. This is clearly a significant investment of time and resources on their side as well there is cost and other resources being set aside from the university as well.

\section{Qualitative Design of the Pilot Study}

The qualitative study was a requirement for a doctoral research course and as such was monitored by a professor. As in any qualitative research study, the researcher is the primary research instrument (Bogdan \& Biklen, 2007). My role was to create and implement all levels of the research study. First, I submitted a proposal to the faculty instructor and worked with her suggestions to come up with an approved study. Once the study was approved it was my responsibility to determine who my interview partners 
would be. I did this by first figuring out which residential faculty members were around in the summer and then decided upon three with varying demographics to more accurately portray the residential experience. While in process of securing meeting times and places for our interviews I worked with my research group from class to design a set of appropriate questions. I received significant feedback from my peers and set up a long list of questions (around 20). I also worked with my group to help identify probing and follow up questions so that I would not be just doing a verbal questionnaire and could conduct a fluid and adaptable interview.

The interviews themselves took place in both faculty residences and an office. Gay (1987) indicates that it is very important to have a consistency to the interview process; both in terms of setting and questions. I asked all of the participants where they would prefer to meet and accommodated their requests. I did not offer any incentives for participating since it was a one-time interview for only an hour. In all three settings my interview partner and I were the only people in the room and it provided a very comfortable environment. All three professors are well respected members of the academic community. The first professor, whom I will call Dr. King, was a tenured education faculty member who has been a residential faculty master for over 10 years. The second professor was a tenured English instructor whom I will call Dr. Jenkins, who had been a residential faculty member for 5 years. The third professor was a tenure-track law professor whom I will call Mr. Johnson, who was completing his second year of living-in. I chose these particular faculty members to examine their perspectives in relation to the amount of time they had dedicated to the experience. I was curious to understand if someone serving as a faculty master for over 10 years would have the same 
perspective as someone who had served less than 2 years. I also was able to get different gender and racial perspectives from this sample as it was diverse in gender and ethnicity. The purpose of this diversity was to see if the data would be divergent based on the avove variables. All of these professors were interviewed once for approximately 60 minutes. All of the interviews were taped, and I created a fully coded transcript from my interview with Mr. Johnson. I have listened to the interview tapes of the other interviews and pulled quotes out that support my findings. I used a color coding system to thoroughly code the transcript. According to Miles and Huberman (1994), coding is used to store chunks of information in categories that would be easy for the researcher to recall. They continue that this is done by the marking of units that cohered because they dealt with the same topic and then dividing them into topics and subtopics. (p. 57). I followed this procedure and utilized different colored pencils and markers to clearly illustrate each individual topic that surfaced.

For the purpose of the pilot study I felt that using interviews would be the best way to get the information I needed. A primary reason I chose this method was because I wanted to get in-depth information on this topic. Rubin and Rubin (2005) gave the following advice in deciding to conduct interviews: "You make sure that both the topic and the research question are best answered through depth interviewing, that what you are asking is important, and that what you propose to do is feasible" (p. 39). I did have some knowledge of the interview partners, but it is limited. According to Bogdan and Biklen (2007) most studies relying on interviewing are with strangers. However, even if the interview partners are somewhat known "a good part of the work involves building a relationship, getting to know each other, and putting the subject at ease" (p. 103). Based 
on the information from the two texts listed, along with feedback from my course professor, it made the most logical sense to utilize interviews to gather a deep, rich base of data on my topic.

Of course, any study is going to present certain issues or concerns that arise over the course of the examination. I think there were a couple of significant issues that arose which I wish I had been better prepared to deal with. However, addressing these issues after the pilot study allowed for me to be better prepared for the dissertation study. The first challenge was the fact that I was in a working relationship with my interview partners. While I was not a direct supervisor to the faculty members, I was, nonetheless, a member of the staff who implemented policies and procedures that directly affected them. I discussed this potential bias with my interview partners who said it did not affect their ability to participate openly. I also feel through member checking I was able to maintain my integrity as a researcher as the participants were able to tell me if I had misinterpreted their words. This problem was significantly rectified for my actual dissertation study as I no longer worked at this university. Indeed, it was an optimal situation as I still had contacts, but interviewees no longer needed to be concerned about how their answers could potentially impact their work environment. I still had rapport with some of the people I interviewed and that had the potential to cause them to guard their answers. I was very diligent in explaining to my interview partners that their information was confidential and that the results helped me better the understanding of impacts and needs felt by faculty. I secured the support of the Chair of the Council of Faculty Masters who helped create the opportunities for me to meet with current and past faculty masters. 
The other problem that arose for me was in terms of the actual questions I utilized for the interviews. While they were well thought out and prepared there was a major flaw for which I was unprepared. I had many questions, but I had not prepared any probing questions or follow up questions based on some of the responses I should have been able to anticipate (see Appendix A). I did follow Bogdan \& Biklen's (2007) suggestion and used semi-structured questions to allow for the most freedom of response from the interview partners while maintaining consistency in the questions. However, I am certain that I missed some opportunities for deeper follow up. To alleviate this problem I have examined the coded transcripts from the pilot study and added some probing questions that I felt might be more useful and appropriate (see Appendix B) which were then used for the dissertation. Overall, I was able to gather some very useful information but I feel I might have gotten deeper answers with better probing questions.

Rubin and Rubin (2005) stated that creating detailed coding is the best way to produce rich and full data from qualitative interviews. I utilized that philosophy in my pilot study after having the three 1-hour long interviews with my interview partners transcribed. I began the coding process by simply reading the transcripts over and over to fully understand what data said. After several readings of the materials natural themes started to form in my thought process based on what the interview partners had discussed with me. I highlighted the emerging themes in different colors and other distinctive symbols to help separate the themes. Since most of the themes that emerged were positive and related to each other I used the same type of highlighter and changed the colors and patterns. I also used a different color scheme for themes which displayed a negative effect. More specifically, I used different colored ink pens on the negative 
themes so the negative and positive themes were clearly distinguishable. Upon conclusion of finding all of the themes I then coded them into categories so I could best analyze the data.

\section{Findings of the Pilot Study}

In my pilot study I found that the experience for faculty was generally very beneficial and clearly outweighed the few challenges that came up. I was able to identify 10 general categories or themes. Of the 10 , eight were positive and elaborated on all the tangible and intangible benefits the faculty members perceived based on their experience.

There were two categories that emerged from the interviews that showed the perceived negative impact on residential faculty.

Time commitment. The first negative category was the idea of how much time it takes to be successful in the position. All three intervieweees mentioned that it took a lot of time away from other things they could be doing. This said, they also recommended that only tenured or "seasoned" faculty participate in the program.

Loss of personal freedom. The other negative category was the concept of giving up personal freedom. Residential faculty members had to get used to "life in the fishbowl" where all students and other staff knew what they were doing at all times.

By far, however, most of the coding categories came out as positive impacts that residential faculty feel they received from their experience living with students. I will touch very briefly on each of the positive categories and then focus on what I identified as the main category or finding. 


\section{Creating Faculty Relationships}

The first benefit category I found was the idea of relationships being created with other faculty members because of this experience. The professors mentioned that they were living and working with faculty members from different disciplines and that they had created great relationships that would have never occurred if it were not for this position

\section{Mentoring Students}

The second benefit category that surfaced was the opportunity to mentor and influence students. All of the professors stated that it was their desire to work with students that was the primary motivation for taking this position on, so this fits perfectly into that idea. Klein (2000) discussed the impact of the residential college system on the opportunity to directly interact and help shape the student experience.

\section{Adult Role Model}

The third benefit category seems very similar, but has it has its own place. This category is just serving as an adult figure. The professors didn't want to be surrogate parents for 700 plus students but they feel good knowing that students and parents alike feel comfortable with the presence that a "seasoned" adult faculty presence brings to the residential college.

\section{Fostering Student Independence}

The fourth benefit category was related to the previous ones, but takes a different direction. This category is assisting students in fostering independence. Astin (1997) demonstrated that students who have contact with faculty are likely to develop and mature at a faster rate than those who do not. 


\section{Improving the System}

The fifth benefit category that came out was being able to make changes to the experience for students and faculty from within the system. The professors explained that before they were part of the residential college program they had no idea on how it even functioned. Afterward, they felt armed with the knowledge and access to high level administrators to help create a new direction for the residential college model.

\section{Formal Remuneration}

The sixth benefit category was the actual payment received - free room and board. While not the primary motivation for any of the faculty in this study this was still an important aspect of the experience for them. Barnes et al. (1998) clearly illustrate that

financial security is an important to faculty both as a general means of survival, but also a feeling of being valued by the institution.

\section{Part of a Community}

The seventh benefit category was the personal benefit of being part of a community. Lindholm (2003) explained that a key to faculty satisfaction and persistence was feeling that they are part of the university community. The faculty interviewed expressed a feeling of strong community of faculty and staff from across disciplines that are all going through a similar shared experience and thus have much in common. They were also part of a residential community of scholars, including students.

\section{Relationships With Students}

The eighth and final category for self-perceived benefits for residential faculty was the ability they have to create out-of-classroom relationships with various students. This theme emerged early and often with all three professors and was also made clear by 
the level of passion with which they spoke on the topic. This general idea is clearly seen by another residential faculty master: "I have an opportunity to have a different type of relationship with students. One not constrained by the organization of the teaching and grading environment and so the relationship I have with the RAs and the residents, except for the residents who are law students, is very different than I have with my students... I have to say I have been very warmly and wonderfully surprised by how our students are willing to take a ride with you into some area or adventure they knew little about" (Johnson, personal communication, 2007)

\section{Discussion of Pilot Study Findings}

The data were very useful in helping me answer my initial research question in a rather clear and efficient manner. My research question asked what the self-perceived impact was on the professors who chose to be residential faculty. That has already been laid out rather clearly stemming from what the faculty masters stated. They were overall very pleased with their experience and felt the impacts on them are numerous and generally positive in nature. They feel they have better relationships with students and other faculty members, get to make a difference in the lives of young people, and receive some nice fringe benefits like free room and board. This is consistent with Golde's (2000) assertion that residential faculty feel better connected to other faculty colleagues and students. Also, in an article I found sharing the faculty perspective on living and learning with campus, Klein (2000) noted "I used to plead with my students to stop by for a conference or a chat; now I can't get them out of my office without polite subterfuge" (p. 13). This seemed to fit hand in glove with the pilot study results I gathered which 
described the residential faculty being able to create positive and unique relationships with students which would not have occurred in any other setting.

The only two negative impacts that came up in discussion were time commitment and the transparency of one's personal life. While the faculty masters acknowledged this as a concern (especially before moving in) they seemed to think it was rather minor in comparison to the incredible opportunity. It was clear to me in the interviews with each of the professors that they were very happy in their current role and were not in any hurry to get away from the residential college.

The pilot study was conducted in accordance with the direction set forth from various qualitative research texts and the literature review and provides information that could be potentially useful to student affairs professionals, administrators, and faculty. I attempted to make the study as trustworthy as possible. I engaged in member checking with my interview partners by sharing with them what I found in my interviews and they concurred that this was an accurate portrayal of their thoughts. I also conducted a literature review and the results are consistent with the findings of my study. Some of this literature review was discussed in the introduction to the study. For example, Ryan (1992) outlined the purpose of the residential college as one that evolved to a concept of community encouraging student development as whole, from intellectual to interpersonal and beyond. Of course faculty members are also going to be concerned about student academic success as teaching courses is the primary mission. Also, a study by Edwards (2002) provides an education look into a couple of other purposes of a residential college. He surveyed students at an institution where they could choose to be part of a living/learning residential community or a more traditional residence hall to look at 
persistence at the university and in the residence halls and at the academic impact of participating in the residential program. His findings were quite clear that there was a significant impact on the students who had chosen the residential living/learning center. He found that students in the living learning center had more than a $10 \%$ higher rate of retention to sophomore year and also had higher GPAs. These results would certainly seem to lend themselves to the hypothesis that students in a residential college tend to feel more of a sense of belonging and community than their counterparts in nonliving/learning centers and do better academically, thus helping restate the case for the need of residential colleges and thus, residential faculty. Given this backdrop, this information can be used to help create future residential colleges, or at least more opportunities for out-of-class student and faculty interaction.

A major challenge in creating residential colleges is finding faculty members who are willing to commit to this lifestyle. The results of the pilot study really provided some concrete examples of the pros and cons from faculty perspectives. This information, especially since it is so overwhelmingly positive, would really be helpful in recruiting new faculty members. The information would be useful both to the administrators recruiting as well as the professors themselves. It is very difficult to get faculty to sign on for so much work when they do not know what the impact will be on their life personally and professionally. It is only fair and logical that all parties involved in the process be knowledgeable about all aspects of the position.

In summary, this study demonstrates evidence that in this setting serving as a residential faculty master provides many positive outcomes for the professors I interviewed for the pilot study. They lived and learned in a community of scholars and 
created relationships they treasure and would not have otherwise. The information from the pilot study may be useful in helping others better understand faculty perspectives when developing or enhancing residential colleges at other institutions of higher education. The main benefit of the pilot study was to create a template to work from for the dissertation. Working from the lessons learned regarding trustworthiness and issues with the questions I was better prepared to set up the dissertation study. The literature review for the pilot study also presented a starting point for the much more extensive literature review needed for the dissertation. While the pilot study certainly did not represent any generalizable findings it did create a vehicle from which to launch the dissertation.

\section{Summary}

The literature review presented clear findings and also shows a distinct gap in the literature which this current study fills. Colleges and universities are clearly looking at the importance of student-faculty interaction and how to promote and facilitate more intentional interaction (Hersh, 1999).

One way institutions are attempting to foster faculty-student interaction is through residential colleges and/or living and learning communities. In these communities faculty spend time with students away from the classroom and help them learn and develop. Research clearly demonstrates that this interaction has an important and positive impact on student success. Students are more likely to persist in college and are likely to have higher self confidence and a broader view on the world and issues because of their intentional interaction time spent with faculty. There is some interesting research that 
points out that while interaction is generally positive for students; it is important to take diversity into account. Students of different genders, racial identity, nationality, etc... may have differing needs and interests in how their interaction with faculty should work.

Clearly for successful faculty-student interaction to take place higher education must find ways to reward faculty for this significant effort. Daly and Dee (2006) discussed the already immense demands on faculty, especially those in a tenure track. Given the amount of work already on the plate of faculty, it is crucial to know what motivates them and helps foster satisfaction. The research on faculty satisfaction and retention point to things one would expect to be factors such as support from colleagues and their department, intellectual stimulation, stress level, and compensation (Lindholm, 2003). Golde (2000) does present a study focusing on faculty-student interaction in a residential setting and the results are promising. Faculty felt very positive effects of the interaction with students in terms of creating collegiality with other faculty and staff and gaining knowledge to become better teachers in the classroom.

In general, the review of the literature provides a strong case for the importance of faculty-student interaction outside of the classroom. This finding was evidenced in terms of students overall and students viewed through the lens of gender or race. The residential college is an ideal laboratory for these interactions to take place. The literature clearly described what a residential college is and the positive outcomes that can result in the intentional interactions therein. More research is clearly needed to understand what the impact is on faculty who live and learn with students. This knowledge will not only enhance the entire experience, but it will help the university better understand what type of faculty are likely to be successful. Thus, the knowledge gained from this study will 
provide information that is very much needed by college and university faculty and administrators as they plan for more and better residential colleges in the future.

In Chapter III, the methods for finding the answers to the research questions are detailed. The methods were determined by examining the research questions and deciding which method would best help find the answer. Kumar (1999) identified structured interviews as a common and very practical way to elicit information in a consistent manner; this method is described in Chapter III. 


\section{CHAPTER III}

\section{METHODOLOGY AND RESEARCH DESIGN}

\section{Restatement of the Problem}

Colleges and universities are working diligently to find the best ways to educate and prepare our students and leaders of tomorrow (Marchese, 1997). Faculty-student interaction has been shown consistently to be a predictor for student success and persistence. The residential college setting is an ideal venue for out-of-class interaction to occur on a regular and intentional basis (Hersh, 1999).

A residential college cannot be successful without able and willing faculty to serve as mentors living and learning with the students. The knowledge gained in this study will provide useful information to both faculty and administrators considering participating in a residential college system.

\section{Research Questions}

This study will focus on providing the answers to the following questions:

1. What are the positive and negative self-perceived effects on faculty that result from the experience of living in a residential college with undergraduate students?

2. What are the positive and negative self-perceived effects on faculty satisfaction and persistence that result from the experience of living in a residential college with undergraduate students? 


\section{Dissertation Research Design and Procedures}

Shank (2002) describes qualitative research as the way to find deep, rich data that can tell a story that numbers could never match. Miles and Huberman (1994) continue: "With qualitative data one can preserve the chronological flow, see precisely which events lead to which consequences, and derive fruitful explanations" (p.1). For this reason, the best method for gaining the detailed and specific information needed in this research was qualitative. It is in this vein that I did a qualitative study which provided indepth information to answer my research questions. Qualitative research has been the logical research method of choice for social sciences for some time because of the ability to use words instead of numbers to represent deep, involved data (Miles \& Huberman, 1994). Data drawn from words provide a great opportunity for new and complicated information to be discovered and explained. Qualitative research provides a great narrative on not only what a phenomenon looks or acts like, but also can explain the linkages or progressions that make the findings likely. For this study qualitative research was also appropriate for the very same reasons. I attempted to explain a complex phenomenon in which several different individuals were asked to reflect upon their own personal experiences in similar, but not identical situations. Given the nature of this research and the need to complex understanding from individuals a quantitative study would not have been be appropriate.

The research data were gathered qualitatively, as discussed previously. Given the nature of the information, it was necessary to determine the type of qualitative research necessary to fulfill my premise. Johnson and Christensen (2004) describe five types of qualitative research: phenomenology, ethnography, case study, grounded theory, and 
historical research. This qualitative study, while having commonality with several types of research, fell into the realm of a phenomenological study.

A phenomenological study is used to describe one or more person's experiences of a phenomenon (Johnson \& Christensen, 2004). In this research the subjects of the study shared their experiences as residential faculty members in a residential college. Lester (1999) explained the purpose of phenomenological study is to identify how the actors in a given situation perceive the phenomenon being studied. In this study I discerned how each of the participants were affected by the residential faculty experience and then pieced that information together to see what common and divergent data emerged in regards to how they were impacted by their experiences. In my role as the researcher, I entered the inner world of each of my interview partners to fully understand their perspectives and experiences It is also important to understand the phenomenological research seeks to describe rather than explain (Lester, 1999). This concept was definitely in keeping with this study. I described the phenomenon of serving as a residential faculty as perceived by the study participants. While I was able to see commonalities in responses from my interview partners and group them accordingly, I did not state there was a causal relationship. Groenewald (2004) also described phenomenological research from the perspective that it is based on the personal knowledge and subjectivity of the participants. He further noted that phenomenological methods are particularly effective at bringing to the foreground the experiences and perceptions of individuals from their own experiences. This is an apt descriptor of my research as was the focus of my study. Going back to the research question, I was looking 
to describe the impact of the phenomenon of serving as residential college faculty from the perspective of the participants themselves.

The research in this study needed to be qualitative, based on the need for in-depth knowledge of the participants. The type of qualitative study was facilitated as a phenomenological study based on the information shared above. With this information now understood, the process for gathering data is described next.

\section{Data Collection Procedure}

13 current or recent residential faculty members from a medium-sized private institution in the southeast with a residential college program of at least 20 years were identified and interviewed. Miles and Huberman (1994) recommend interviewing as the most logical and common method of qualitative information gathering in phenomenological studies. Interviewing has its advantages and disadvantages. Some potential disadvantages are the fact that the quality of the data will depend upon the quality of the interviewer and the interaction itself (Kumar, 1999). Conversely, some advantages of the interview as a method of data collection, also according to Kumar (1999), is the fact that the interview is more appropriate for complex situations, is more useful for collecting in-depth information, and the questions being asked of the subject can be explained if necessary (p. 115). Rubin and Rubin (2005) continue that train of thought stating that through interviews complex answers to questions may be found. In this study, for example, interviewing was necessary to determine faculty members' personal perceptions regarding their experiences. While quantitative data could be collected about how long they stayed in their positions, the only way to understand how 
the experience affected the participants was through the process of intentional and consistent interviews with the individuals involved in the study.

Once it was determined that interviewing was the appropriate way to gather data, I had to decide how many interview partners were needed for the study. I chose 10-15 interviews based on other qualitative studies utilized in my literature review and ended up interviewing 13. The intention was to provide the correct number of interview partners that will allow for complete saturation on the topic. Creswell (2003) describes saturation as the point of data collection at which no new themes or ideas will generally materialize. I am also basing the 10 to 15 number on both my pilot study and a review of the literature to for this study. In the pilot study three people were interviewed and even among that small sample there was much overlap in data categories. In the literature review, for example, Johnson and Christensen (2004) recommend in-depth interviews with 10 to 15 people. Given this information, 13 interview partners help me get to that point of saturation.

The 13 interview partners were chosen from the private institution I mentioned previously. This institution is medium sized with approximately 12,000 students. Approximately 4,000 of the students reside on campus in either apartments or one of the five residential colleges. This is a selective university in the southeast with a history of residential colleges going back more than 25 years. All of the students residing in the residential colleges are undergraduates with the vast majority of them in the traditional college age range of 18 to 22 . The residential colleges range in size from 450 students to over 900 students. There are three residential faculty members in each residential college. The faculty master is the lead faculty member in the community and serves to set the 
intellectual tone for the community. Each faculty master has the opportunity to work in conjunction with the administration to appoint two associate faculty masters. The associate masters are generally responsible for programming for students and assisting the faculty master in generally promoting a living and learning environment with the students. The master and associate masters work in conjunction with a full-time professional residence coordinator. The residence coordinator is the primary administrator for the community assuming responsibility for student conduct, staff supervision, emergency procedures, and other such duties. The residential faculty and residence coordinator serve to work together in forming the leadership team of the residential college. There are a total of 15 residential faculty members at the university. The Chair of the Council of Masters (the organization comprised of the residential faculty) assisted me in contacting each of the faculty to invite them to participate. I accepted the first 13 faculty members who volunteered to participate. I did not anticipate the need to provide an incentive to the interview partners. The Chair assured me that this is a topic they were passionate about, and they were very happy to participate. I also member checked with them and offered to share the findings of my study. Given that they are all academicians this was of interest to many of them.

I obtained authorization from the Institutional Review Board (IRB) from both my university as well as the other university before the study began. I traveled to the university and conducted individual interviews with each of the faculty members who agreed to participate. I interviewed each faculty interview partner for 90 minutes in his or her office or residential college home after having them sign a statement of informed consent. The 90-minute interview was based on the approximate time the interviews took 
during the pilot study (60 minutes), given that some additional probing questions were added. I held structured interviews with my interview partners. According to Johnson and Christensen (2004), structured interviews are defined as the investigator asking a predetermined set of questions. This provides in-depth information, but also adds to the trustworthiness of the data as the questions for each interview partner are consistent.

As mentioned, each interview partner was given the statement of informed consent in advance and was asked to sign before the interview began. According to Gay (1987), the informed consent is given to research participants to understand the purpose and scope of the study in order to decide if they wish to participate. The consent form was sent to the interview partners in advance so they were fully aware of the study before they committed the time and energy to the project (see Appendix C). The timing and placement of the interviews themselves was a result of a combination of debriefing the pilot study and Rubin and Rubin's (2005) suggestion that interview times be consistent with participants and be a reasonable commitment from the interview partner. I conducted the interviews over the course of one month. Also, I allied myself with the Chair of the faculty masters who assisted me in the coordination of the interview schedule. Bogdan and Biklen (2007) discuss the importance of creating a relationship with your interview partners, but wars that it is crucial to consider any bias the researcher may have when working with people who are known to them. While I have a rapport with the Chair, most of the other faculty were people that I had limited interaction with as many of them were new since I last spent time at this institution. My rapport with the chair helped me secure interviews, but did not impact the nature of the interaction with my interview partners. However, I disclosed to them my prior relationship with the 
university and asked them if they felt comfortable proceeding with the interview. I also explained to them that I was conducting member checking with them so they could challenge my interpretation of what they had intended with their responses. I also shared with them that I would be participating in peer review with someone unaffiliated with the study or institution for a completely unbiased source of feedback. I recorded the interviews (with permission from my interview partners) and also took field notes.

\section{Data Analysis Procedure}

Once the data were collected, the data were transcribed by a professional. Once the transcriptions were complete I triangulated them with my field notes as well as read the transcripts as I listened to the recordings to make sure they were accurate as suggested by Kumar (1996). Miles and Huberman (1994) describe triangulation in the following way: "Stripped to its basics, triangulation is supposed to support a finding by showing that independent measures of it agree with or, at least, does not contradict it." (p. 266). To help in this end, I compared my field notes and transcriptions with the data to make sure I had not misinterpreted any interview data. On a larger scale I followed Christensen and Johnson's (2004) data triangulation process by conducting several interviews following the same, consistent method and questions to examine the consistency of the themes that emerge from the data overall from all of my interview partners.

Clearly, transcribing and coding the data is crucial to the ability to have the deep, rich data necessary for this study. With the consent of my interview partners, I recorded all of the interviews. I worked with a professional transcriber who transcribed the interviews into formal transcripts. In conjunction with Rubin and Rubin's (2005) 
suggestion, the process began by my reading the transcripts completely several times before even attempting to segment and code the data. Upon multiple readings, "segments" of information began to stand out. Segments, according to Johnson and Christensen (2004), are data chunks that are parts of the body of the transcript that form meaningful analytical units on their own (p. 502). I utilized the segments and themes that surfaced in the pilot study as a starting point and added the new themes which arose and incorporated the new segments that fit into the existing themes. Upon conclusion of identifying the segments for an entire transcript I conducted the coding process to identify all the themes and other pertinent issues.

Coding is the system of marking segments of data with symbols, descriptive words, or category names (Johnson \& Christensen, 2004). The method I utilized to identify these segments and place them in categories was using different colors and patterns to serve as the symbols. For example, all data segments relating to increased ability to teach were highlighted in green. This is the process that I utilized in the pilot study and thus I followed that process again during the dissertation study. Kumar (1999) recommended that utilizing a consistent coding system that is comfortable for the researcher is the best way to approach that aspect of the study. I also utilized field notes written in the margins during the interviews to help identify potential links between segments as part of the coding process as described by Bogdan and Biklen (2007). I also prepared a master list of codes to tie all of the transcripts together. The master list, in accordance with Miles and Huberman (1994), included each code followed by the full code name and a brief description or definition of the code. As each transcript was coded, 
any newly identified codes were added to the master list creating an efficient manner of storage and quick access for the researcher.

At the completion of the process I analyzed the data to find the patterns and themes that emerge to describe the findings of the study. As Johnson and Christensen (2004) suggest, I tied together the segments of information that have been placed into different categories. In the pilot study, the categories that emerged were positive and negative self-perceived impacts on the residential faculty. I began with those categories, but kept open the likelihood that other categories were likely to emerge as more personal perspectives were introduced and analyzed. The data were examined to answer my two research questions. While the first question was very open ended and lent itself to multiple categories, the second question needed more clarification. Clearly, my second research question led me to examine faculty satisfaction and persistence. In terms of faculty satisfaction, I examined the data and looked at coding segments that matched what Barnes et al. (1998) described as the major elements of faculty satisfaction: feeling like part of a community and feeling valued. Faculty persistence was examined through the lens of how serving as a member of the residential faculty impacts the faulty member's desire to stay at his or her current institution. I utilized all of the individual transcripts and data to triangulate the overall findings. For example, if just one person described a certain phenomenon I listed it accordingly. However, if all or most of the participants described an effect this position had on them similarly, it will be somewhat more generalizable to this particular group of residential faculty. Once I had this part of the study completed, I facilitated member checking to give the participants an opportunity to improve the trustworthiness of the information as well. Member checking, 
according to Rubin and Rubin (2005), is the process of sending the findings back to research participants and allowing them the opportunity to challenge the way the researcher perceived their input into the study. Once the member checking was concluded, I confirmed that the data were consistent with what my interview partners actually stated. Member checking helped me correct for any potential bias I may have had as the researcher. By checking back with my interview partners, they were able to correct any information I may have interpreted differently than they intended. I also implemented peer review to combat potential bias on my part, by having a colleague review my work. Peer review is described by Gay (1987) as describing one's interpretations and conclusions with one's peers or colleagues. I incorporated peer review with a colleague at two points in the study. I discussed the general themes that emerged from the coding process to see if he had a different perspective on that. I worked through my final conclusions and implications with him as well. I identified a colleague at a different institution willing to spend the time to assist and in no way related to my study. Once this process was complete I moved on to the findings and implications part of the study.

\section{Summary}

The pilot study experience helped me create a systematic approach to gathering and analyzing the data for this study. However, it also presented some opportunities for improvement in the dissertation study. One important change was to restructure the interview aspect of the dissertation study. The location of the interviews worked well with the faculty; however, the questions utilized were not quite sufficient. The updated questions (Appendix B) were more focused and also contained more probing questions 
that were important to be prepared with (Rubin \& Rubin, 2005) in order to obtain a deeper level of data. For example, in the pilot study I asked the question "what drew you to be involved in a residential college?" Reflecting on the literature and pilot study interview experience, I realized that there was a need to add probing follow-up questions. For this question, I added the following probing questions: (a) Who approached you to become involved and how? (b) How did you feel your relationship with students would change? and (c) What concerns crossed your mind? As previously touched upon, I learned that it is important to utilize the resources I had to help cultivate the 13 interview partners I utilized for this study. With the pilot study, I was able to just call and get on calendars. Later I was at a different university and did not know most of my potential interview partners. I was fortunate to have secured a promise from the Chair of the faculty masters that he would work with me to lend credibility to my request and ensure that I would get the participation I needed for the study. Again, I needed to correct for any potential bias I may have had because of this relationship and also make sure that my research partners understood my experiences with the program.

Overall, the pilot study was a platform from which to launch research for this dissertation. The general plan worked well and the interview partners were comfortable with the process. However, the experience showed me some areas that needed to be augmented to be better prepared for the study. The pilot study experience, in addition to some changes implemented from that process, left me well prepared for this dissertation study. 


\section{CHAPTER IV}

\section{PARTICIPANTS AND FINDINGS}

\section{Participants}

The purpose of this study was to examine the effects residential faculty members reported as a result of their experience living in a residential college. The university was able to provide me with a list of 27 current and former residential faculty members for whom contact information was available. I emailed all of these individuals with my proposal abstract and a brief explanation of my interest in interviewing them for the study. In the end I was able to sit down and formally interview 13 current and former residential faculty members who served as faculty masters and/or associate faculty masters as they were the only people to respond. There was a strong element of diversity in faculty who participated. The participants ranged in time of service from current members of the residential college system to participants from over 20 years ago. Eight of the 13 participants were female and 5 were male. Most of the faculty members were tenured at the time of service, but there were a couple of exceptions. The faculty came from a variety of academic disciplines and points in their career. There was also a variety of ethnicities represented by race, religion, and national origin. Overall, the group was very diverse, yet, even from this diversity there were consistent themes that emerged. I will give a brief and general description of each participant for context of the study using a pseudonym for each person. Each participant was given the option to pick his/her own pseudonym or allow me to choose one for him/her. The pseudonyms selected were created without regard to ethnicity for further protection of participants. Thus, a pseudonym that may sound as if it is from a certain ethnicity could be placed on any 
participant, regardless of his or her actual ethnicity. For further protection of confidentiality as promised in the study, I will not confirm whether or not any of the participants are current of former residential faculty, nor will I mention whether or not they were faculty masters or associate masters. This will allow for context without identifying characteristics of the participants involved.

Professor Theresa Martinez - Dr. Martinez was a residential faculty member who brought a family with her to live in the residential college. She knew about the residential college system because of interactions she had with other faculty who had served as residential faculty. Dr. Martinez was a tenured professor at the time of involvement in the residential college system and was teaching undergraduate students. Coming into the position she was very excited about creating a better appreciation and understanding of campus and was a bit apprehensive about how the time commitment would create challenges for her and her family.

Professor Margaret Jones - Dr. Jones was a residential faculty member who also brought family with her into the residential college when she moved in. She became aware of the residential college system as both a student at a university that also had a residential college system and appreciated its potential and also through colleagues who spoke of their experiences in the residential college at the university examined in this study. Dr. Jones was a tenure-track professor at the time of service in the residential college, but had not yet achieved tenure. She taught mostly undergraduate, but also some graduate students in her academic program. When considering the position she was excited about the opportunity to interact with students and also happy with the conveniences living on campus could provide. Her real only concern coming into the 
residential college was the uncertainty of how this experience would affect her privacy and that of her family.

Professor Shawna Cook - Dr. Cook was a residential faculty member who also brought her family with her to live in the residential college system. Her knowledge of the residential college system was initially a result of being asked to come into the college as guest lecturer and presenter for programs for students. She supplemented this knowledge by current residential faculty to inquire about the experience and what the expectations would be. Dr. Cook was a tenured member of the faculty and was teaching several courses with both graduate and undergraduate students. She was very intrigued by the idea of blending both her work and personal life in a convenient, yet intentional way. She also thought it would be a beneficial experience for her children in terms of the exposure to the university and students. Her main concern at the time of appointment was figuring out exactly what she was supposed to be doing in her new position.

Professor Marta Weeks - Dr. Weeks was a residential faculty member who came to the residential college system with her immediate family. She came to know and understand the residential college program through members of her own faculty department who had both participated in the system and who were well aware of the program through colleagues who had served as residential faculty. Dr. Weeks was a tenured faculty member who taught mostly graduate students, but also had a desire to teach and learn more about undergraduate students as well. She was motivated to take on the position because she felt it was going to be an excellent way to get to know the university better and get to know students on a more personal level than as a professor. 
Her only real concern was that she was not sure what the actual responsibilities of the position would be, so she wondered if she was completely prepared.

Professor Alexis Pierre - Dr. Pierre was a residential college faculty member who brought family with her to the residential college. Dr. Pierre heard about the residential college system and the residential faculty position via faculty in her college. They knew she was not happy with the living options in the area and thought with her disposition towards students this could be a nice alternative. She was a tenured faculty member teaching mostly undergraduate students. Upon learning more about the opportunity she felt it would be a really unique way to learn more about the university and students, while also providing a convenient place to live. Her biggest concern was that by moving onto campus that she would lose her ability to separate between work and family life. She felt moving into a "fishbowl" could be challenging for her family due to lack of privacy.

Professor Robert Jenks - Dr. Jenks was a residential college faculty member who brought a family with him to live in the residential college. Dr. Jenks was made aware of the residential college system by the dean of his college, who thought this experience would be one he would enjoy and would also be a bonus that would make him want to commit to staying at the university. He was a tenure track professor teaching both graduate and undergraduate students. Dr. Jenks was first thinking about the tangible benefits the position provides such as free housing and food and the convenience living on campus could provide his family and himself. After learning more about the system he found he was intrigued by the opportunity to live on campus with students. He heard from colleagues it was a valuable experience for their professional development and learning. His only real concern coming into the position was how the opportunity was 
going to impact the privacy of his family. He was concerned about letting students come into his home which could decrease his personal time with his family, which was very important to him.

Professor Simon Temple - Dr. Temple was a residential faculty member who brought his immediate family with him to live in the residential colleges. Dr. Temple first found about residential colleges and residential faculty as a guest lecturer in the colleges. He had no idea the residential colleges did anything except give students a place to sleep, and as he learned more about the system he began to contact administrators to find out how he could get involved. Eventually he was asked by other residential faculty to join the system. Dr. Temple was a fully tenured faculty member teaching mostly undergraduate students. He believed the experience would be good for him professionally in learning more about the residential side of student life, and he also thought the atmosphere of a residential college would be one that would have a positive effect on his children—living around bright and ambitious college students. His only real concern was the fact that he felt he was not sure what the position entailed and what the expectations of him would be.

Professor Jean Lanscomb - Dr. Lanscomb was a residential faculty member who brought her immediate family with her to live in the residential college. She found out about the residential college program from current residential faculty who contacted her about potentially becoming involved in the program. She also had at least one colleague in her department who had previously served in the residential colleges and was able to provide her with a lot of information regarding how the program worked and what it would be like to participate. Dr. Lanscomb was a tenure track professor who taught 
mostly graduate students and thought it would be a great opportunity to learn more about and better connect with undergraduate students. She also had come to know a few of the other residential faculty members and was excited about potential connections with them as well. Her biggest concern coming into the position was privacy issues. She thought that students would have a tremendous amount of access to her apartment and wondered how that might impact her family.

Professor Merideth Vann - Dr. Vann was a residential faculty member who did not initially bring a family with her in the residential college system. She actually found out about the residential college system through talking with other faculty members. Upon finding out more about the residential colleges and the residential faculty role she took it upon herself to contact administrators to find out how she could get involved with the program. She was a tenured faculty member who taught mostly undergraduate students. Dr. Vann was optimistic that the residential college would not only provide a keen insight into the lives of undergraduate students, but also provide a community of which she could feel a part. Unlike many others, she was not concerned about lack of privacy as that was actually a draw for her. Her only concern was that she felt she did not have much information on what the position would actually entail and as such, she was not sure if she was fully prepared to succeed.

Professor Patricia Barry - Dr. Barry was a residential faculty member who moved into the residential college with her family. She actually found out about the residential college due to her own interest in participation. She had heard of the system and began contacting current and former residential faculty members to get a better understanding of the program. She also had at least one colleague in her academic college 
with experience serving a residential faculty member. After gathering information on the opportunity she took it upon herself to contact the administration to formally request an interview to explain how she could benefit the students by serving in the residential college. Dr. Barry was a tenure track professor teaching mostly undergraduate students. She was excited about the opportunity to get to know students in a different way and on a different level. She felt it would help her better understand the students she was teaching. Her biggest apprehensions moving into the residential college system were how the opportunity would impact the privacy of her family, and she also was unsure how she could possibly interact and create relationships with all the students in the building, given that there were more than 700 of them.

Professor John Steele - Dr. Steele was a residential faculty member who did not initially bring his family with him when moving into the residential college system. Dr. Steele was recruited to be part of the residential college system by a current residential faculty member. He had very limited knowledge of the residential colleges until he was invited in to participate in a staff meeting with students to learn more about the experience. Shortly after this experience he was invited to join the residential college system. Dr. Steele was a fully tenured professor who taught students both on the undergraduate and graduate levels. Prior to his involvement he was excited about what type of interactions he would have with students. He felt this would be a unique and powerful way to connect with and support students. He was one of few faculty members who was not concerned about privacy as he embraced that part of the opportunity. However, he did think the experience could have a detrimental effect on his personal life with friends outside of the university, given the amount of time needed and the fact that 
he was living on campus. He was also slightly concerned that he was not really cognizant of the actual responsibilities the position would entail.

Professor Dean Smith - Dr. Smith was a residential faculty member who moved into the residential college and brought his immediate family with him. He had been involved in student life as an undergraduate and graduate student and found this a way to continue that involvement with students. He found out about the residential college system from colleagues in his department. At least one of his colleagues had served in the residential college system and gave him perspective about the position. He was optimistic about the position based on his previous experiences and perception that a residential college was a very dynamic community where he could mentor students to be successful. His initial concerns coming into the position were time commitment and preparation. He was already very busy in his professional role and was unsure how much time would be required to make an impact in his position. He was also fairly new to the university and was thus unsure if he had the knowledge base of university resources necessary to help students who needed such information.

Professor Jose Wilson - Dr. Wilson was a residential faculty member who moved into the residential college and brought his immediate family with him. He was aware of the residential college system due to relationships with colleagues that had served in the residential college system. He was approached by university administration to consider the position. He was considering positions at other institutions at the time, and he believed some of the interest in his candidacy was to help keep him at the university as a professor. He was a fully tenured faculty member teaching primarily undergraduate students. He was intrigued by the potential to influence students in a positive way and 
also the tangible benefits that associated with the position for both him and his family, along with the impact of living in the residential college community could have on his children. His two man concerns coming in were how open the university was to change if ideas were put forth and he wished to have a clear understanding of roles and responsibilities between faculty and administration in the residential colleges.

\section{Findings}

This section outlines the results taken from the data resulting from the 13 interviews conducted with residential faculty members. The results were to be connected or shown as divergent to the literature review conducted for Chapter 2 of this study. There were many themes that developed from the coding and analyzing of the data and those themes were broken down finally to four major categories: Living on Campus, Relationships, Impact on Job, and Institutional Knowledge. Each category contains differing aspects covered in that area. Each category lists both positive and negative impacts as self-reported by the faculty members interviewed.

The findings will be presented generally for a full understanding of the data and then will be presented in a more narrow scope in relation to the research questions posed for the purpose of the study.

\section{Living on Campus}

Perhaps the most basic tenet of serving as a residential faculty member is the fact that he/she will be physically living on campus in a residence hall, referred to as a residential college in this study to signify participation of faculty in the residential community. The interview partners in this study found living on campus had a significant impact on them in both positive and negative ways. 
Tangible/physical benefits. Residential faculty in this particular institution receive a fully furnished, rent-free apartment, meal plan, weekly maid service, parking passes for guests, and other minor benefits. Every faculty member interviewed stated that this benefit, in and of itself, would not be reason enough to participate in the program. However, several of the faculty members did clearly see this as an important part of the experience. Professor Jenks, for example stated:

My initial thoughts in accepting the position were about the selfish benefits. And that, again, everything from not having to worry about buying or renting a house, maintaining a house, and all the stuff that comes with that." He continued in stating that "the benefit is a place to live, and that's worth it" and that unfortunately, if there are no other benefits other than better connection to students, then it is not going to happen.

Professor Jones also discussed the importance of the apartment: "Number one right away was the financial benefit. It was really great. I was thinking, you know, this is great for our lives and to not have to worry about our rent or mortgage." Professor Jones also discussed a couple of other benefits that seemed particularly important:

The other benefits, you know, even down to the dining hall benefit are great. I was always dealing with people and interacting with them and really enjoyed that. Also, the maid service once a month was incredible to simply allow me to do what I needed to do because it is really working two jobs a lot of the time. Thus, all of these benefits had impact in our lives in big ways.

Overall, in all of the interviews, there was a unanimous affirmation that, at the very least, the apartments were a nice benefit. Some discussed the housing as a major benefit and some said it was not a factor in joining the residential college system, but all acknowledged the accommodations were nice and a benefit in some way. In fact Professor Weeks summed it up this way: “The support we get here is amazing, just like that at the university level. We are treated so well that if anything goes wrong in the 
apartment, they're here to fix it in 2 seconds. The accommodations are beautiful, even the meal plan is beautiful."

Convenience. A benefit perceived by several of the participants of this study demonstrated that they felt the convenience of living on-campus was a significant plus for them. The reality for them is that the college campus is its own little community and being there and near their offices is a very positive benefit of being a part of the residential college system. Faculty members are often extremely busy and overscheduled (Daly \& Dee, 2006). The opportunity to keep work and home close was seen as a benefit to this challenge. Professor Cook described the importance of this benefit:

For me, one of the factors that made me think I could handle it was the proximity to my office. So we are here at home, and the office is just right there. I could just get in and out and, and as I said, I had young kids. So just the thought that I could be so close to them when I was at work was very appealing to me. The idea that I can kind of blend my work life and my home life influenced my decision.

Another telling quote by Professor Smith describes the opportunities living on campus can afford:

I understand that I had many reasons for wanting to live on campus. I like the accessibility that it always has to things on campus. There is no more dynamic place, I think, in the country than a university. In fact, one night you can go see a play, another night you can see an orchestra performing, and another night you can go see a poetry reading, and another night you can go see students perform, and another night, you can have some of these same students in your apartment. I love that accessibility.

Professor Vann described the benefits in a little more personal way in how it can

affect the day-to-day life of a faculty member:

Let me tell you, it is so nice to live on campus. I love the library, and it is so easy to go the library; I am a voracious reader. It also very convenient to get to the gym on a more regular schedule. I mean the gym is 5 minutes away. We also have a cinema on campus, which, you know, brings documentaries and-I'm always short on time - so I think this convenience saves me so much time. For example, I 
know they show 15 minutes of ads so I leave the house when 10 minutes of ads are done, and I walk in just as the film is starting. I've got it timed perfectly, and then if I don't like it, I just walk out and I haven't wasted too much time, you know, so it seems that being on campus is just incredibly wonderful.

Loss of privacy. In the description of the faculty participating in the study was a note about a concern they had prior to moving into the residential college community. The most common response to that question was lack of privacy. Thus, when the data were examined regarding actual experiences, it is not surprising that lack of privacy did actually come out as a concern for some, though not all, faculty. This finding is consistent with Golde's (2000) finding that illustrated a consistent faculty concern in considering living in a residential setting and the potential effect it could have on their personal life.

An example of this concern was put forth by Professor Jenks in describing a challenge with loss of privacy: "I get frustrated because I feel like it's potentially taking away the protection of family time and family space." Professor Pierre continued: "My biggest concern is that sometimes it's nice to have separation between your work life and your home life, and sometimes living here on campus, you felt that the minute you opened your door you're kind of like living in a fish bowl."

All of the participants described the amount of interactions they have with students. Generally, that was a very positive thing and also one of the main attractions to the position. However, this can also cause a challenge to the personal time and space of the residential faculty. The following thought by Professor Smith clearly shows an example of this: "Working here can be tough if you can't separate your personal life from your work. I think I can do that pretty well because once I leave the office, I'm gone for the day until I come back. The problem with that is that our apartment is used, for 
example, probably 14 to 15 nights a month for student events. Now that affects your family dynamics, of course." The professor continued: "I mean none of the stuff here belongs to us. Anything in our apartment, the dishes, the stuff is not ours, and it's there for student usage also. It's part of teaching young people how to share and respect other people's living space.”

\section{Relationships}

Another key finding area of the study can be described in terms of relationships. Relationships, especially with students, were a key factor in the initial decision for the faculty to move into the residential college. While this was, in general, a very positive benefit for residential faculty, there was one concern area that was noted by a few of the faculty members.

Family/children. The majority of the faculty members participating in this study moved into the residential college system with a family. The family units varied from spouses, to parents with young children to adolescent children. However, most of the families did come with younger children and felt that this experience had a very positive effect on the children and family itself. For example, Professor Wilson stated:

It was an absolutely fantastic experience for my spouse and our kids. We probably had students in our apartment a minimum of four times a week, if not more. I would say to every RA to come join us, and they took advantage of this. They would bring four or five other students, and prepare dinner with our family that night. My family would eat and interact with the college students in that way. The main result for my kids was that they became very comfortable speaking with adults.

He continued with an interesting anecdote: "The youngest child went on to " $\mathrm{X}$ " University and was very critical of their residential college system as she thought it was 
inferior to ours. Perhaps it did not live up to her implanted memories as a child of what we did."

There were differing reasons given for what the positive impacts on family were.

Another example comes from Professor Cook:

Well it worked out very well for me because my children were very happy to be living on campus. It became a status symbol for them. Their friends loved coming and visiting them on a university campus and thought it was very cool. So they thought they had died and gone to heaven. I mean they tossed the football with football players, and then they could go back tell their friends about it. They also participated in a lot of the activities and went on the busses with students and got to experience things that none of their classmates or friends did. They felt like they were college students.

Another view on the positive impact on family was offered by Professor Barry:

My kids, my youngest and especially the oldest, I think, would have been quite shocked had they not lived in the residential college. He and my spouse have very quiet personalities. This experience of living in a residential college made them much more extroverted. They feel so connected to the youth. Even if both my spouse and I worked at the university we wouldn't have felt the connection to the University. Now, they are very proud of the university and feel like they are a part of it.

Another benefit Professor Barry discussed was the exposure to diversity: "It had such a strong and positive impact on them. One thing for me that was so important and continues to be is that that position afforded my children and my family an opportunity to interact with one of the most diverse environments. “

Sense of community. Barnes et al. (1998) described that a major factor in faculty satisfaction and persistence is faculty feeling they are part of a community. That community could be defined by department or the university community as a whole. Thus, the finding that faculty members felt a benefit of serving as a member of the residential faculty is an increased feeling of community, is certainly positive. Nearly 
every faculty participant mentioned in one way or another how feeling like they are part of a smaller community was beneficial, and, for some, it was very enlightening.

One perspective about community was in terms of the physical surroundings, such as living in a residential community. Professor Jones described her perspective of the community:

I mean, I remember the first week I moved to campus. We strolled around the campus to get a better feel of our new community. Somebody was tuning their instruments, there was an international dance troupe practicing. We got to the bank, post office, the convenience store; it was like a having a little city in our own back yard. There was also a huge open green space, the field, watching kids play all kinds of sports, the water, the ducks, and the classrooms all together in one community.

Another way community was explained was in terms of the people around whom

a community formed. Professor Cook stated:

You do learn something about the meaning of community living on campus that I didn't have in the city itself, in my old neighborhood, so I think I sought out opportunities in my new neighborhood to bring that kind of feeling. When I moved into another community, the residential college system helped me connect with my neighbors because of the experience of community I felt in the residential colleges. This was a fabulous feeling and I hadn't experienced it before.

Professor Vann provided the following thought on community:

To me, the biggest benefit of all, I wanted to have people around me and this was a great chance to have young people around us. The other benefit, of course, is I come back to the residential college and I immediately have a family. If I get lonely, I just have to step out and there's somebody behind the desk you know, and I can just take a book out there and read just like I do at home with family.

Relationships with students. The most common reason given by faculty in this study for participating in a residential college was to create relationships with students. This is consistent with Philpott and Strange (2003) who identified in their study one of the most rewarding benefits of participating in a residential college system was the 
relationships that they had formed with students. Hersh (1999) also noted that residential colleges are an ideal place to create out-of-classroom relationships between faculty and students. The variety of responses from the participants ranged from personal relationships as a benefit of the interaction to mentoring relationships.

One perspective on the benefit of relationships built with students was succinctly summarized by Professor Lanscomb:

You are in a community of hundreds of students from all walks of life and so it allows you to kind of put aside some of those things and have closer relationships with people. I probably wouldn't have had relationships, and I think the same is true for students, if it weren't for this opportunity. I developed relationships with students that I would think I would otherwise have had nothing in common with. The relationships ran the gamut, but I definitely have relationships still maintained with some of them, you know, mentor-mentee where I provided a lot of guidance emotionally or professionally and stay in touch with still. I did also develop friendships, particularly with the RAs, who I am now socially friends with and maintain deep, meaningful relationships, which is great. One way faculty described the benefit of creating relationships was joy and

positive feeling they had being able to serve as a mentor. In this role they were able to help students find ways to overcome hurdles and be more successful. Professor Martinez described one aspect of this benefit:

So I have students come in and ask me questions like 'are you allowed to have a baby when you are in graduate school?', and all of these misconceptions that students have. A lot of people think 'I don't want to be a professor because I want to have a family.' So, I can say to them, OK, just look around and see all of us with families and very successful academic careers." This quote demonstrates the power residential faculty have as mentors to make a significant contribution to individual students' lives.

In addition to mentoring, some faculty felt another benefit was just knowing that they had helped students succeed in college. Professor Barry explains:

I love discussing issues and concerns with students. And so the reward for me is to have that extension of the parameters, so to say, of the conversation. So that's been the greatest reward for me, helping them to have a better experience in 
college. If I didn't think I was helping them in some way, I probably wouldn't have taken this position. So, for me it's extremely rewarding as well to know that hopefully some of their college experience is a little less frightening because of their relationship with me. They are like 'wow, my professor is a real human being.'

This final example sums up the feeling some of the faculty shared with me about how helping students is such a significant reward for them. Professor Pierre shared this experience:

I met a student on the first day of move-in. She has a whole little group of friends that she moved in with and seemed to not have a care in the world. A year later she emailed me and explained that she was having some financial issues and asked for assistance. I know she is pretty shy, and I know that from appearance her family circumstances would not have occurred to me had I not created a relationship with her. The professor, because of the relationship with the student, was trusted enough by the student to ask for assistance. This was an extremely gratifying experience to know what a direct impact could be made on the student because of the relationship.

This example is also congruent with Philpott and Strange's (2003) findings discussed earlier. Many faculty feel it is a significant benefit to be able to have meaningful relationships with students.

Relationships with faculty. All of the faculty members in the this study discussed at some point the benefit of creating relationships with other faculty members, particularly faculty members from different disciplines that they would have never had the opportunity to meet if not for the residential college experience. Daly and Dee (2006) described rapport and relationships with other faculty as an important predictor of faculty satisfaction and retention. Professor Cook shared this perspective:

The relationships that I built with other faculty, that was probably the best part. So I developed very strong friendships with faculty outside of my department, faculty with whom I would have not socialized or would not have done things with and that was pretty special and those relationships remain, so that was great. 
Another perspective on the deep relationships formed by faculty in the residential colleges was offered by professor Lanscomb:

The other two families in our residential college, we developed a very close relationship and these are relationships that would not have occurred otherwise; but since we lived together and spent most of our time together, we became very close. This really enhanced the experience for us, and I think made us a better working team as well. We now have football tickets together and our kids are growing up around each other. My life has been forever changed by the relationships with the other faculty. These are people I'm going to be close with and my child will be close with for the rest of my life and that's a huge selling point for being a residential faculty member.

Professor Steele also noted the importance of the relationship with faculty, but

was a little more focused on the pragmatic benefits:

I know we are very collegial group; there are many that I see socially. So, it's what we make of it. I do know people who kind of just sit back and you don't see them as part of the group. But for me I can pick up the phone, I can send an email, and contact any of them to get what I want or need to get for a student, and that's a major point. You know we come from all disciplines in arts and sciences, from medicine, from law, whatever. The relationships I have with the residential faculty only serve to enhance my work with the students here.

The fact that all of the faculty members reported some type of benefit in building relationships with faculty is consistent with Vito's (2007) residential study which clearly showed the same results. That study, as previously described, examined the perspectives of faculty involved in a residential college and shows that there is some commonality in the experience for residential faculty from two different programs.

Relationships with parents. There were multiple faculty members interviewed who described the relationships created with parents as a benefit. This was somewhat unexpected as this theme did not come up at any point in the review of the literature. Nonetheless, some faculty members described relationships as fond and beneficial, 
especially in terms of just making them feel good about helping parents adjust to their children in college.

For example, Professor Barry described the relationships this way:

One of the biggest things I saw out there was that parents have such a feeling of relief when they see us. They're like 'OK, there's actual real adults here.' I created relationships with parents that were just great. I had a parent meet me at the college parents' weekend and also taught one of his son's classes. The next week his son introduced himself to me and described how happy his parents were to know that I was there for him a professor and also a residential faculty member. I received many calls and emails from parents and was able to direct them in the right place, which was very rewarding.

Professor Martinez offered a similar perspective:

I think parents love that there are old people there who have, you know, kids. They see us safe and I feel badly for them sometimes because if you look them deep in the eye you can see them asking you to look out for their kid. I think some of the most meaningful interactions I have had have been with parents.

Loss of outside friends. By and large the residential college experience generated significant relationships. They reported positive relationships with students and other faculty and an improved sense of belonging to a community. The one negative impact that was noted by faculty in this study was the loss of friendships with people outside of the residential college system. This was due to several factors but mostly the amount of time taken up by the position and the amount of new relationships formed by faculty created less time for existing relationships and friends. Loss of outside friends was not a topic that was found in a review of the literature for this study; however, a couple of quotes from the faculty will give the rationale clearly.

Professor Steele clearly articulated the concern friends had about the residential faculty position: 
I think my friends, however, on the outside were concerned about me taking on this position. But they were more concerned because they thought it was going to take me away from them, and they would see me less when I moved onto campus. In the end it probably worked out the way they thought. I really didn't factor in how much time, you know, meetings in the evening and such...

Professor Vann related that it was just so easy to get caught up in the residential college community and activities that outside friends and relationships were put on the back burner:

The other part that suffers a little bit is your social life outside of the University. So, you know, friends complain that you don't want to do things with them, and you only want to do things on campus. I remember I was invited to a wedding and it was the same date as a major residential college event. I went to the wedding, but then didn't stay for the reception because I was asked to participate in a couple of the events and I didn't want to cost my college points in the competition. Hopefully, if I could do it over, I probably would go to the reception.

Impact on Job. In interpreting the results for this study this area was the most volatile. There were some consistent themes that emerged, but there were also some divergent responses; and conflicting themes. While there were a couple of significant negative impacts shared, all faculty would do the position again if they had it to do over.

Improved ability to teach. Consistent with the findings of Vito (2007), every faculty member interviewed for this study felt that participating as a residential faculty member increased his/her ability to teach students. The reasons for this varied from just better understanding students to actually viewing them as human from the experience. Philpott and Strange (2003) also found in their study that faculty who connect with students outside the classroom and especially in a residential college report gaining knowledge and skills that make them better professors.

Professor Jenks described the impact serving as a residential faculty member can impact the ability to teach: 
I feel like I have more insight into their lives in general. I have more insight into what's important to them and what's not important to them. Everything from just music to social issues and events and relationships. So I think it impacts my teaching significantly. I think I am able to make my classes more relevant to their lives. There's something about this position that lessens the power dynamic a little bit between faculty and students. The lessened power balance, I think, follows me into the classroom and that helps me fine tune my teaching with what I am learning about a student's life and student development.

Professor Lanscomb offered a similar thought:

"I think it enhanced my job by really kind of broadening my understanding of what my students' lives were really like and being able to play that educational role not only in the professorial style, but also to educate with other experiences and other aspects of my personality. I think it made me a better professor because I was able to really kind of get a closer look at what their lives were like.

Some of the other residential faculty members went into a little more detail on how exactly this experience helped them become better professors. For example, Professor Steele offered:

I think I've almost become an expert on what makes a college student tick. I mean, without having them in a formal classroom I have still seen the differences in students over the years. They are all 18 years old but continually changing, like now with the influence of technology and such, I just get to learn a lot about them.

Professor Martinez similarly describes tangible benefits to teaching as a result of

the residential college experience:

The most surprising thing for me has been that I had not thought it would enhance the other part of my job, the teaching. I find that when I am designing curriculum and studies I am much better at generating examples that I know are meaningful to undergraduate students that I wouldn't have otherwise known. Also, I feel like I am a more meaningful teacher, and I can through my day-to-day teaching sort of enhance the students' lives in a lot of ways. I am very happy and grateful for that, so that has been a great surprise for me.

Improved satisfaction/retention. One of the key questions of this study and the

few similar studies I have found is how does the experience of serving as a residential faculty member impact the overall satisfaction and retention of those individuals. All 13 
of the faculty members described the experience as a positive impact on their satisfaction and/or retention. There are differing levels of fulfillment from crucial to helpful. In addition, every person interviewed stated that they would absolutely do it again given the same circumstances. This positive response is consistent with studies by Golde (2000) and Vito (2007) which also showed faculty participating in residential programs with students improved their satisfaction.

Professor Vann felt passionately that the residential faculty experience actually kept her from leaving the institution:

I tell everybody that I would have left the University if not for this opportunity. My colleagues are very nice, but nobody has time and they all have family. I probably would have left. It would have been hard to imagine not being in that environment for a few years. It has really affected my happiness positively a lot, particularly in my first 2 years. The first year was a bit of a struggle, but the second year on was very nice because of the opportunities to interact with people.

Faculty members in higher education are the key element to the university. It is incumbent on a university to have quality faculty members to be successful (Marchese, 1997). It is also been shown that faculty who are more satisfied are more likely to stay at their university, even when receiving other offers (Lindholm, 2003). Thus, the following two responses give a strong indication of how important this experience was to them.

Professor Steele related the following:

This experience impacted me tremendously. Previous to this experience I had weighed heavily the idea of leaving. And there were a couple of things right there that I was looking at. But I had just moved in here and liked this so much that I just stopped looking for anything else. You know, I think my satisfaction with the University was just so much greater. So, you know, to know students on a personal basis, to know parents and that's made just a hell of a big difference. And I think most people would probably say that is the key.

In a similar vein, professor Martinez added: 
I thought about a couple of opportunities. I was being recruited from a couple of other universities. I was given one firm offer, but I didn't want to leave as I was afraid it would lessen my interaction with students, a passion I developed working in the residential college. In the end, being part of the residential college made me feel more a part of the university community. I think I might not have stayed here if it wasn't for that experience. I think it changed my commitment to the University in a very meaningful way.

Impact on faculty performance. While every participant in this study enjoyed the experience of being a residential faculty member and would do it again, there were those who found it did have a negative impact on their faculty job performance. This was particularly noticed in terms of research and writing for a few of the faculty members. Daly and Dee (2006) did note the tremendous pressure on faculty to write, publish, and research, and the reality is that for some residential faculty members this was a challenge while serving in the residential colleges.

Professor Cook put it this way:

My productivity declined considerably during that time in the residential college. I would have considered extending the position or going to another residential college; the main reason I didn't do it is was because I knew that professionally I would not have been able to handle it. The reality is I published less while I was living on campus and attended fewer conferences, and I knew I couldn't continue to do that.

Professor Weeks explained a similar scenario:

I mean, I think that, giving a really genuine answer, yes, it was difficult. I am in a high productivity department and so the expectations of me in terms of publications and grants and it's one of the top funded departments and so for me personally it's difficult. I didn't think it would be realistic to be in good standing there and stay in the residential college for the long run, so that could hurt me in the long run, but for a couple of years I think it is fine.

The impact on faculty performance area also brought a discussion point from several faculty members that they would not have been able to participate had they not been tenured at the time. As Professor Cook noted earlier some of the tenure process 
performance indicators did suffer for some faculty during their time in the residential colleges. Professor Temple stated:

The reality of the situation is that I would have never been able to take this on if I was not already tenured. The position seems to take on so much of your time and I don't think my department would have fully supported my sacrificing my research for this.

Time commitment. Most of the faculty members in this study did indicate that there was a significant time commitment involved in the position. While most faculty members found ways to overcome this issue some have found this to be a significant negative impact on them. Cox and Orehovec (2007) noted that universities are already very complex organizations that require time management skills to navigate, and the added time commitments for residential faculty can be challenging for some. However, there were several faculty members that stated that while there was a significant time commitment, it was something one can work through as one gains more experience.

Professor Martinez discussed actual impact on time is a result of serving as a residential faculty member:

Yeah, I would say time was the biggest issue. You know, things I did not think about when I started the position. I don't know that it has added anything other than more time. Again the time thing comes back to just knowing so many more students than you would otherwise. So, again, my office hours are jammed, and I am writing recommendation letters for a lot of people that I wouldn't have had to do otherwise.

Professor Smith offered a similar response: "Time commitment was the biggest concern for me. Also, we have events in apartment so much, and you feel some pressure to be part of those events. One month our apartment was used for programs 26 different nights." 


\section{Institutional Knowledge}

The final findings category was that of institutional knowledge. This area showed both positive and negative impacts in terms of institutional knowledge and serving a residential faculty member. In general, faculty did not come into this position considering institutional knowledge as a concern or a benefit. However, while many participants discussed the first two themes, all weighed in heavily on the final theme which will be discussed shortly.

Better knowledge of the university. Almost all faculty members in this study shared that participation in the residential college system had afforded them a deeper knowledge of the university as a whole. They felt they learned much more about the university than they ever would have as a "regular" faculty member. Johnsrud (2002) noted that a factor for faculty satisfaction was feeling connected to the university and feeling like they have a strong knowledge base of how the university functions.

Professor Weeks clarified the importance of the benefit of institutional knowledge in the following statement:

I didn't know anything about residential life, and so that's another example of just getting to know who the players are a bit better. Then when you have students in your office stressed out about housing issues, you know who to refer them to. It is a huge benefit to just have a clear understanding of the resources on campus and know who the key players are. This position has given me new insight into the University. I am much more aware of the resources that are here; I heard about everything happening on campus in staff meetings and felt very connected to the University.

Professor Pierre added to the point from an employee perspective:

It would be this idea that you would just get a much more realistic and total view of the institution. I mean, I am an employee of this institution so that to me it is hugely beneficial to be able to see this whole other side of things that is available 
and the kind of experiences that students have; I guess that would be the biggest thing you really want to know from your employer.

The following reflection by Professor Temple is a good example of what other

faculty reported in this area:

This experience will make faculty understand the University in way they never would understand it as a faculty member. It will have them connect to the university community in broader ways and some of the things we talked about in terms of interdisciplinary faculty and also just that and just office that I didn't even know existed before I moved into the residential college.

Politics. While faculty consistently reported learning more about the institution and the key players via this experience, there were those who did not always see this as a good thing. Some of the faculty reported that from this position they were exposed to challenging political situations that they were not subjected to as faculty in their own department. Philpott and Strange (2003) related in their study also that while faculty enjoy meeting new people and key players, unfortunately, some of the political and bureaucratic things they are subjected to in the role of residential faculty can be unpleasant.

In this statement by Professor Jones described how knowing more about things is not necessarily better:

I think in some ways I probably found out too many things, and it made me have negative perceptions of the University. I think being on the inner circle I was able to see favoritism and nepotism; I was able to see the inner workings of how things go on in the greater administrative point of view. I think probably the insight impacted me negatively. I became part of the university, but with that comes some knowledge about the institution that I would have rather not had.

\section{Professor Pierre examined politics from a position of how it can impact}

others: 
So that is the negative part of learning this whole other side of the University. It's sad because for some people on the other side of the University their jobs are... I think life's almost not fair for the faculty to go all in on something because we have tenure, and then our job is not on the line. However, you realize someone else's job might be on the line, even if you just having an innocent conversation and it gets twisted around. It could affect someone's livelihood, so that's the negative.

Professor Jenks puts it in a little more general terms:

Just being involved in some of these meetings, I get more insight into where some of the problems are, some of the bureaucratic problems and some of the politics come from. That happens everywhere, but I think because I have been involved in this position it has exposed me to some of the underbelly of the University.

A different type of politics was mentioned by a couple of former residential faculty who felt they were not appreciated after they left the position. For example, Professor Wilson stated:

I feel like we are treated poorly after we leave the position by the university. My former masters, and I have never said no to anything that was asked of us and yet we are never allowed to give back. For example, I tried to bring back a former master to speak to students who was very successful at a different school and received heavy resistance.

Lack of training. The final area of finding for this study is that of lack of training for residential faculty in their positions. Lindholm (2003) discussed the importance of faculty feeling supported to be successful. Again, faculty in the study all said they enjoyed the experience and would do it again. However, all faculty members interviewed also said they felt as if they were not adequately prepared to take on this position, and that it was really just a matter of figuring it out for themselves.

Professor Smith described his frustration with the lack training in the following way:

I would have said coming into it, I didn't know enough about what it took to be successful as residential faculty member. There was no blueprint, there was no 
book, and there was no one to tell me what the right and wrong things to do were. Also, if I didn't have the guidance of someone who had been her for a significant amount of time it would have taken a lot longer time for me to understand the onsets of the job and what it really meant to serve in the position.

Another perspective was tendered by Professor Martinez:

I think understanding what the job expectations are has been a bit of a challenge. I think there is no handbook of what you are expected to do as a residential faculty member, and I think sometimes people are hesitant. There is this weird perception that you don't tell faculty what to do, when in fact I think faculty would love to know what the expectations are and if there were any concrete objectives and goals. We talk around it a lot with discussions about it, but it hasn't of yet resulted in anything concrete, and so I think that is a little bit challenging - not knowing if you are doing what you should."

Finally, professor Weeks added this:

I would have liked an orientation. I really did feel overwhelmed not knowing what was expected of me, and everyone else in the residential college for that matter. It took me a year to go through the cycle to know what is expected. 


\section{CHAPTER V}

\section{DISCUSSION AND IMPLICATIONS}

\section{Summary of Study}

This study was initiated to examine the self-perceived impact of serving as a residential faculty member. As noted by Marchese (1997) higher education is continually looking for ways to better educate and impact students. Students today have more choices than ever in deciding where and how to obtain a college degree. Many colleges and universities have moved toward to the creation or recreation of residential colleges (Alexander, 1998) in order to create a learning laboratory for students. According to Astin (1993), learning and general success for students are positively impacted by out-ofclassroom interaction with faculty members. It is in these residential colleges, with residential faculty, that some of the most intentional connections can occur (Hersh, 1999).

However, it takes foresight and effort on both sides to result in a positive outcome for faculty and students. The creation of the residential college is not possible if the college or university cannot persuade faculty members to also participate in the program. In this study 13 current and former residential faculty members were interviewed to glean their perspectives based on actual experience. It was hoped that information would be useful in helping potential residential faculty members gain some insight from those who have already experienced it.

This study was conducted at a medium sized private institution in the southeastern United States in the spring of 2011. There were 13 current and former faculty members who each participated in a 90 minute qualitative interview. The interviews took place on 
this campus over the course of several weeks. Participants were given the opportunity member check and also were given the option to pick a pseudonym or have one provided by the researcher in an effort to keep confidentiality. Once the interviews were completed the process of coding and examining the data commenced.

\section{Research Questions}

While the general findings have already been categorized and presented, following are more specific responses to the research questions presented at the beginning of the study.

1. What are the positive and negative self-perceived effects on faculty that result from the experience of living in a residential college with undergraduate students?

The four major topics of findings were (a) living on campus, (b) relationships, (c) impact on job, and (d) institutional knowledge and the corresponding 16 smaller subsections were all self-perceived impacts on the residential faculty as a result of their participation in the residential college system. However, in an effort to provide clarity, the results will be very briefly summarized.

This study found that residential faculty reported multiple ways that their experiences in residential colleges have impacted them. Those themes have been broken down into four general finding areas:

1. Living on Campus - The actual physical location of living in residential colleges was seen to be very influential. The first impact on faculty was financial. The free apartment and meal plan proved to be very beneficial and an attraction for the position. Another important aspect of living on campus was the convenience of it for faculty. They described how it can improve the quality of life with such easy 
access to work, entertainment, social opportunities, and so forth. Finally, the negative impact in this area was a perceived loss of privacy. Some faculty were concerned that because of their physical location and the fact that events happen in their apartments, it can have a detrimental impact on their personal and family lives.

2. Relationships - There were several positive and a couple negative aspects to this impact area. Many faculty members found that the residential college environment had a positive impact on their children and families in general. Being around college students helped the children learn and grow. Many of the faculty members also described the sense of community in the residential colleges to be a major benefit. They enjoyed the camaraderie and feeling of belonging. All of the faculty members highlighted relationships with students as a major benefit of the position, in fact, it was why most of them accepted the opportunity in the first place. Helping relationships with parents were also seen as a benefit by several participants. The only negative impact in this area was that it was reported by a few faculty members that they lost touch with friends outside of the residential college world as a result of this experience.

3. Impact on Job - A major benefit discussed by nearly all participants was the fact that this intense experience with students helped them become better professors. They felt they better knew what made students tick and had a little more ability to see them as fellow humans. As will be discussed more in Question 2, faculty definitely felt this position increased their overall satisfaction and in some cases led directly to them staying at the institution. There were a couple of negative 
impacts from the experience reported by faculty. Several of them reported that they were less productive on the writing and research side part of their professorship. A few mentioned that this was a factor that limited how long they were able to serve in the position. All of the faculty members also addressed the concern of time commitment. To some it was a significant issue, while to others it was just part of the experience that needed to be ironed out.

4. Institutional Knowledge - The final benefit area began with faculty members sharing that they felt a better connection to the university and also the resources available to them for both themselves and their students. However, there were negative impacts that came with that in terms of dealing with political and bureaucratic issues. They felt they were kind of sheltered as faculty members and this opportunity exposed them to some the unpleasant stuff in working with higher administration. There was also unanimous concern about a lack of training. They felt, overall, they were just kind of "thrown into the fire" and expected to succeed without knowing what success event meant.

The second research question was addressed very briefly in Question 1, and is expanded on below.

2. What are the positive and negative self-perceived effects on faculty satisfaction and persistence that result from the experience of living in a residential college with undergraduate students?

In short, all participants in this study stated that participating as a residential faculty member increased their overall satisfaction. There were multiple areas with satisfaction was greatly enhanced. Satisfaction was impacted in the four major areas as 
previously discussed. Satisfaction was affected both positively and negatively, but far and away the positive outweighed the negatives for the faculty members, thus the reason that all of them would do it again. There was a significant positive impact on retention in this study. Multiple participants in the study stated that they were seriously considering looking for other positions or were even entertaining job offers from other schools. However, because of the powerful experience they had in the residential college system and the connection they felt with the university community, they decided to stay at their current institution.

\section{Conclusions}

In this particular study the residential faculty members who participated felt that the experience in the residential college was very impactful for them in a myriad of ways. The study seemed to also show that while there were positive and negative impacts for the faculty members as a result of serving in the residential college system, most of the impact was very positive. As noted earlier, all participants were definite that they would do it again if they had the opportunity to rethink or do it over.

Rubin and Rubin (2005) described interviewing as the art of hearing and listening to interview partners. They posit that after collecting thorough data, deep, rich themes will emerge. That was certainly the case in this study. Some themes emerged nearly unanimously, while others were based on several interviewees. These themes led to the conclusions on the value of the data that were collected. Much of the data are supported by the literature review; however, there were a few themes that emerged that appear to be new to literature. 
Probably the most sought after finding in this study will be the overall impact on faculty satisfaction this position created. Fortunately, the finding is that the impact was very positive for all faculty members in the study. In the only study similar to this identified in the literature review, Vito (2007) had the same finding. In Vito's (2007) study faculty members shared that the intentional interactions with students were probably among the most positive experiences of their professional careers. They also identified a significant increase in personal satisfaction resulting from this experience. This is also consistent with Golde (2000) whose study focused not necessarily on residential faculty, but faculty who are in an intentional program to create relationships with students in a living and learning community. Even without the residential aspect from the faculty, faculty members still acknowledge positive effects from the interactions with students outside of the classroom.

In terms of persistence at the institution, the data also presented some positive results. Several of the participants in the study clearly stated that they stayed at the institution because of the residential college experience. In fact, some of them had pending offers they declined due to the experience. This is consistent with the literature and is quite a significant finding. Using Lindholm (2003) as a model, if faculty members feel more of a "fit" with the institution, the odds that they will stay at the same school increase significantly. In the case of this study, all of the faculty members described a better connection with the university as a whole. Thus, when these ideas are linked, the fact that faculty in this study did not want to leave, even with competing offers, because of their increased contentment is logical and consistent with previous findings. This finding is significant for institutions looking to create residential colleges or recruit new 
faculty to work with residential students. While one must be careful about the generalizability of a small sample such as this, it is significant that the results are consistent with Vito (2007) and Golde (2000). At the very least, the study creates a starting point for discussion with faculty contemplating working in a residential college.

Another important conclusion that can be drawn from this study, especially when coupled with the literature review, is that faculty who participated in a residential college, both from this study and the literature review, reported a significant increase in their ability to teach. Teaching, for most faculty members, is a very important aspect of their career and even seasoned, tenured faculty members clearly indicated increased teaching skills. Again this finding was consistent with the similar studies conducted by Vito (2007) and Golde (2000). Similar to this study Vito (2007) found that faculty cited becoming more flexible, creating more concrete syllabi, and generally being able to relate better with students as a result of their experience with outside the classroom involvement with students. Philpott and Strange (2003) also noted that faculty connected to residential students also found that the experience humanized students and in that way made it easier and more rewarding to teach them. They talked about a renewed sense of purpose and enthusiasm for teaching students. Again, this is an important finding when recruiting faculty to participate in residential colleges or in justifying residential colleges and/or programs in the first place. Klein (2000) pointed out that one of the main concerns in creating residential colleges is as simple as cost. Marchese (1997) added that higher education is more accountable than ever to the public. One way to help justify the costs of creating residential programs is to describe the benefits. 
The literature is clear and convincing that out-of-classroom interactions between faculty and students have a positive benefit for students (Astin, 1993). However, this study, along with similar studies identified, are beginning to show that faculty are also positively impacted by this experience. When the two key stakeholders in higher education are both gaining from something, it follows that the idea should at least be explored for feasibility.

Barnes et al. (1998) found that feeling like part of a community was crucial to faculty satisfaction, and thus persistence. For faculty, community could be defined as community within his or her specific department or the university at a whole. In this study residential faculty acknowledged the positive impact of feeling part of a community on several levels. First, they felt more a part of the overall university community. They felt they were much more in the know and confident that they were part of what was going on. They also felt a significant sense of community among fellow faculty members in the residential college system. They found both personal friendships and professional networks developed that would not have occurred without their involvement on campus. The faculty members also discussed increased satisfaction due to their family being positively affected by the environment. Again this finding is consistent with Vito (2007), Golde (2000), and Philpott and Strange (2003). In an environment where institutions want to keep their best faculty, it would make sense to share this information with them and recruit them into living/learning centers or any other intentional linkage with students outside the classroom.

There were many other benefits identified by faculty in this study that emerged as findings. Those findings include positive effects of a free apartment and meal plan, the 
convenience of living on campus, new and exciting relationships, and a better overall understanding of the University and its key players. Thus, residential faculty members had far more positive impacts to share than those that were negative or frustrating. However, since nothing is perfect, there were a few negative or challenging findings. In this study all faculty members shared that the time commitments in being a residential faculty member are substantial. For some faculty members, that was a major challenge. It was such a challenge that it actually caused a decline in their productivity as a professor and researcher. For other faculty members, it was simply a matter of adjusting to a new schedule. According to Johnsrud (2002) and Daly and Dee (2006), time demands on traditional faculty are already very intense and are a factor in faculty satisfaction. This challenge is noted before considering the responsibilities added by serving in the residential college system. While every participant in this study stated they would do it again in the same situation, there were a few who stated clearly that they had to stay in the system for a short period of time because of the negative impact the time commitments had on their job as a professor. One professor basically said that while the residential faculty position was rewarding, it did negatively impact his productivity as a faculty member and that was the purpose for which he was at the school. Several of the faculty members also noted that they would not have been able to take on this position had they not already been tenured. They were of the opinion that their individual departments would not have supported their involvement and it could have actually jeopardized their tenure process.

A challenge that was universal to the faculty in this study was the lack of training and/or understanding the expectations of the position. The faculty members generally 
described some version of their experience that included being "thrown into the fire" with no tangible training or plan to be successful. They all managed to adjust and have a good experience but found that this issue set them back on time it took to become acclimated to the position. Lindholm (2003) discussed the importance of fit and faculty satisfaction. The residential faculty did feel some incongruence with their fit initially due to the frustration of feeling unprepared. Many of the faculty members also commented that although they became comfortable in their role and enjoyed their experience, they never received direction or feedback to tell them whether or not they were doing things in accordance with University expectations.

In summary, several conclusions can be drawn from this study, especially when coupled with the literature review. The residential faculty members all describe their experience in the residential college positively. While there were some challenges such as a serious challenge in time management and a perceived lack of training, the positive impacts from the position superseded those challenges. Faculty members in this study, and in the correlating studies cited, found their satisfaction rose because of this experience. They were happy with the tangible rewards like the free apartment, but even more so they felt the position positively impacted them on significant issues such as becoming a better instructor, creating new relationships personally and professionally, and having a better understanding of and connection to the University. Several participants in this study also clearly remarked that if it were not for this position, they would likely have left the institution for another job; but this position had such a positive effect it helped them decide not to leave. The faculty members in this study described the residential faculty position as very impactful to their personal and professional lives. 


\section{Recommendations for Practice}

The results of this study indicate that the residential faculty position is challenging, yet very rewarding. The fact that all participants enjoyed the experience to the point that they would do it again is quite telling. Similar to the findings of Vito (2007), faculty who participated in the system felt they gained skills and experiences along with positive impacts on their personal lives in a close-knit community and felt that they were part of the University community in general. While serving as a residential college faculty member was shown to be positively impactful for faculty as discussed in my study and those identified by Golde (2000), Alexander (1998), and Vito (2007), there are a few suggestions for improvement in practice.

\section{Sharing of Information}

The first recommendation for practice is simply sharing the information with the University community along with prospective students and parents. Several members of the residential faculty in this study commented that most of their colleagues they talked to had no idea what the residential colleges were like. In fact, a couple of them stated that colleagues and even department chairs found their involvement as residential faculty a waste of time. Barnes et al. (1998) discussed faculty satisfaction also in terms of institutional reputation and faculty rewards systems. It would seem to follow logically that given the evidence of student success (Astin, 1993) and increased faculty satisfaction (Golde, 2000; Vito, 2007) garnered by the residential college system, that sharing that information intentionally with the University community would reinforce the importance of the program. In so doing, it would likely also increase the interest in future potential residential faculty members. 
While a bit of departure from the purpose of this study, it would also be a good idea to share this information with prospective students and parents. On the one hand, sharing this information in this way would be good for recruitment in general. Cox and Orehovec (2007) noted that there is a perception that faculty do not spend much time with students. This information could help reinforce the positive relationships that occur in the residential colleges. For example, the finding that faculty develop positive relationships with students in residential colleges would be comforting to parents worried about "adult" supervision of their students. Also, the finding that residential faculty perceived a strong sense of community in the residential colleges would be likewise comforting to parents and students alike. There is so much clear evidence on how this program can positively impact students (Astin, 1993; Lundberg, 2004; Sax et al., 2005) that it would make sense to showcase it.

The residential faculty benefit to sharing this information goes back to the notion of institutional reputation as offered by Barnes et al. (1998). If incoming students and parents are aware of the program they will pleased that such a system for success exists. Along with that, they will have a positive view of the residential faculty which increases the opportunities for relationships and also makes the faculty members feel more appreciated and part of a reputable program.

\section{Time Management}

As previously discussed, time commitments are a significant challenge for residential faculty. They are already swamped with meetings, deadlines, teaching, and research (Daly \& Dee, 2006) before they even consider stepping into the residential faculty role. All members of this study found that the issue of time management and 
demand for their time was a significant issue. Cox and Orehovec (2007) also noted that faculty members often are challenged to connect with students due to the multiple stressors in their day to day existence.

There is not simple solution to this problem; otherwise, it would likely have already been solved. Part of the answer to this problem is addressed in the final recommendation, and that is to clearly define the role and scope of the residential faculty position. Most faculty in this study commented that they did not really understand where their role began and ended. The often felt that they just figure it out; it is different in every residential college. Thus, something as simple as a clearly defined job description and training would assist faculty members in adhering to that description. A huge benefit for residential faculty is that they have full-time professional student affairs personnel also living and working in the college with them.

A second part of this recommendation would be set recommended limits for usage of faculty space and time. This recommendation could come in the form of a suggested policy coming from administration with limits on times apartments could be available, suggested meetings to attend, reaffirmation of the priority of the faculty position before the residential faculty position. Of course, these would be only recommendations for faculty but it would create a baseline expectation for usage of their time and space. The suggested policy would allow the faculty the ability to say "no" to requests without looking like the bad guy. They could just say, "I'm not really supposed to come to that many meetings, sorry,” for example.

Another recommendation is that support staff should be appropriated to help the residential faculty members sort through all the requests and demands on their time. The 
support staff should handle appointments for faculty members and handle general correspondence in order to deflect requests or route things that do not need to get to the faculty members. Several faculty members reported responding to many requests for meetings and assistance where they do not feel they are the appropriate person to respond, yet get involved because they want to offer assistance and be polite. Routing communications through support staff could take some of those unnecessary and timeconsuming tasks off the plate of the residential faculty and help them retain focus on their faculty position and the responsibilities clearly outlined for them in the residential college.

Finally, I recommend that tenured faculty be the priority in filling new residential faculty positions. Several faculty members clearly stated that their productivity in terms of publishing and research went down during their time in the residential college. Some went so far as to say they would have never taken on the position had they not already been tenured. The participants also shared that departments had varying levels of support for their participation in the residential colleges. Given this data, I don't think it would be optimal to potentially risk something as crucial to a faculty members career as tenure. Perhaps if it were possible for the university to restructure faculty rewards during the tenure track process to include service to students and the university then this position would be more amenable to tenure-track faculty. Until that time, it seems a bit of a risk for non-tenured faculty to take on the role of faculty master. 


\section{Training}

The need for training and guidance was a very clear result of the study. Faculty members felt very frustrated that they were unsure of what they were supposed to do and how they were supposed to do it. As Lindholm (2003) expressed, fit is a crucial part of faculty satisfaction and it is very difficult to have a fit in a position when faculty members do not have an understanding of how to do their job, or what their job actually entails.

Vito (2007) described the training process for residential faculty as challenging, but crucial. The challenging part is developing a training program which is truly comprehensive, yet inclusive. To do this, information must be shared by both student affairs professionals and current and/or former faculty masters. Interestingly, in this study a couple of former residential faculty commented that they wished they had been asked to give feedback or advice to new faculty members to help them succeed. One interview partner went so far as to say that there was feeling of detachment and separation after leaving, as if he was never there from the University perspective.

Therefore, training should be set up with input from student affairs, current and former residential faculty, and upper administration who would like to create a tone for the training and perhaps give the group a charge. Due to time limitations, as described by Daly and Dee (2006), the physical training should be done over the course of the day or 2 days, prior to the beginning of the arrival of the students. Another concern put forth by the faculty participants was the lack of a "handbook." Student affairs should be charged with creating an actual "residential faculty manual" which lays out the basic information they need such as policies, procedures, basic residential college history and information, 
emergency protocols. This handbook should be based on residence life training, but expanded to include important contacts (including former residential faculty who are willing to be mentors) and words of wisdom for residential faculty over the years.

Another frustration several faculty members mentioned over the course of the interviews was the uncertainty of responsibility. To solve this upper administrative management should convene a meeting with the leadership of student affairs and residence life along with current residential faculty to flush out a clear job description for residential faculty. A step has already been taken with residential faculty signing a contract outlining some general timelines and responsibilities (Appendix D). However, a more detailed contact outlining day to day responsibilities an division of responsibilities with student affairs staff would be helpful. This would alleviate the frustration of uncertainty and make it easier for the residence life and residential faculty members to work together and not have to try to negotiate who should do what.

Following these fairly simple training recommendations would eliminate much of the frustration faced by residential faculty. They could be provided with a manual upon accepting the position and look through it slowly over the summer to get a feel for what they are supposed to do. They could also contact former and/or current residential faculty members and have some introductory discussions about the journey they are about to embark upon. This way, when they go through the training right before they actually start they will have some baseline knowledge and the training will be more about filling in the gaps, reinforcing ideas, and beginning to create connections. 


\section{Limitations of This Study}

This study demonstrated the impact serving as a residential faculty member had on this group of faculty members. The findings created strong themes which can be logically interpreted. Based on this information conclusions were drawn and recommendations made. However, Miles and Huberman (1994) clearly stated that a phenomenological qualitative study is not generalizable. Thus, this study is able to give rich information and conclusions. However, it is not necessarily a predictor of experiences of different residential faculty at different institutions.

\section{Further Studies}

As noted in the introduction of this study, there are very few studies with a focus on the faculty perspective regarding faculty-student interactions outside of the classrooms. Hersch (1999) noted that many colleges and universities are moving toward creation or least exploration of residential colleges or living/learning communities. Clearly, for that to happen, faculty must agree to participate in the programs. This study demonstrates that this particular group of faculty members was positively impacted and felt an increase in overall satisfaction with their institution. This was also corroborated by the studies of Vito (2007) and Golde (2000). However, there are still very few studies in this area. Research at more types of institutions and just more studies in general would be a needed addition to the topic.

The literature review indicated that there is very little information out there on how serving as a residential faculty member impacts the faculty. There is an incredible amount of information available on how faculty-student interaction affects students, but precious little the other way around. Hopefully, the findings of this study will prompt 
more studies on residential colleges or residential programs and how they impact the faculty. Though the findings of this study echo the findings of a few other small qualitative studies, more information is needed to add to the discussion. Large scale quantitative research would be useful in helping to supplement the findings of the few studies on this subject. While lacking the detailed information of qualitative studies, quantitative research can examine a more specific research question (Creswell, 2003), perhaps following up by the findings of this study and attempt to show that it a generalizable finding.

There were some topical areas in the findings that would certainly lend themselves to further study. One topic I mentioned briefly was tenure. There needs to be further on study on the impact of living in a residential college for faculty who are not tenured and how this position impacts their position as a faculty member. Another area of study that would add to the literature in this area would be to examine the impact of living in a residential college for faculty in terms of demographics. It would be important to know if women, men, and faculty of differing ethnicities and sexual orientations were similarly impacted by the position. Finally, the impact on the spouses/partners of the residential faculty would be important to know as well. The faculty in this study all had concerns about the amount of time taken up by the position. Given that dynamic, it would seem logical that partners would feel some of that impact, along with some of the benefits as well.

\section{Summary}

This study set out to examine the self-perceived effects faculty describe in relation to serving as a member of a residential college. A discussion of the history of residential 
colleges and the faculty roles therein provided the background information to the current interest in re-establishing residential college and/or living/learning centers.

The importance of faculty-student interaction was discussed in the review of the literature, along with faculty satisfaction and retention. There was a pilot study done previous to this study and that study was briefly highlighted to give some background into the current study. Based on the literature review and the pilot study, the qualitative methods were developed and then implemented. Finally, the data were collected and examined to create the findings from which the conclusions and recommendations were drawn.

In brief, the conclusions drawn showed that the faculty members who participated in this study felt significantly impacted by their experience in the residential colleges. The majority of the impacts were positive and included better teaching skills, better connection to the university, and better satisfaction overall with the institution. The few negative effects were loss of privacy and time, and for some, there was a negative impact on productivity in research and writing. Faculty members also felt they needed more training to be successful. In the end, all faculty members interviewed stated that it was a positive experience, and they would do it again the same situation.

Finally, based on the findings, some basic recommendations were made to make the position even more rewarding. Those recommendations included more vigorously marketing the program and results of this study to the university community and potentially students and parents contemplating joining the institution. A second recommendation was to find specific procedures and personnel to ease the administrative burden placed on residential faculty, who are already very busy with a full-time 
professorship. Finally, the recommendation for more intentional and consistent training was put forth.

These few recommendations would aid what is already perceived as a very successful program by the faculty members who participated in my study. Given the focus on residential colleges nationally and the importance of faculty satisfaction overall, it is hoped that this study will have helped lay some groundwork to a better understanding of how the two groups of stakeholders - faculty and students — can create a mutually beneficial relationship. 


\section{REFERENCES}

Alexander, F. K. (1998). From Oxbridge to the colonies: The development and challenges of residential colleges in American public universities. In F. K. Alexander \& D. E. Robertson (Eds.), Residential colleges: Reforming American higher education (pp. 36-52). Seattle, WA: Boeing Company.

Astin, A. (1993). Four critical years: Effect of college on beliefs, attitudes, and knowledge. San Francisco, CA: Jossey Bass.

Astin, A. (1999). How the liberal arts college affects students. Daedalus, 128, 77-101.

Bogdan, R. C., \& Biklen, S. K. (2007). Qualitative research for education: An introduction to theories and methods (5th ed.). Boston, MA: Allyn \& Bacon.

Barnes, L.W., Agago, M.O., \& Coombs, W.T. (1998). Effects of job-related stress on Faculty intention to leave academia. Research in Higher Education, 39(4) 457-482.

Boyer, Earnest. (1999). The Earnest L. Boyer laboratory for learning: a model of effective faculty involvement in residential programming. Journal of College Student Affairs, 19(1), 35-44.

Cox, B. E., \& Orehovec, E. (2007). Faculty-student interaction outside of the classroom: A typology from a residential college. The Review of Higher Education, 30(4), 343-363.

Creswell, J. W. (2003). Research design: Qualitative, quantitative, and mixed methods approaches (2nd ed.). Thousand Oaks, CA: Sage.

Daly, C \& Dee, J. (2006). Greener pastures: faculty turnover intent in urban public Universities. Journal of Higher Education, 77(5), 776-803.

Edwards, K., \& McKelfresh, D. (2002). The impact of a living learning center on students' academic success and persistence. Journal of College Student Development, 43, 395-402.

Gay, L. R. (1987). Educational research: Competencies for analysis and application. New York, NY: Macmillan Publishing Company

Golde, C. M. (2000). Understanding faculty involvement in residential learning communities. Journal of College Student Development, Jan/Feb, 225-240.

Groenewold, T. (2004). A phenomenological research design illustrated. International Journal of Qualitative Methods, April, 1-27. 
Hersh, R. H. (1999). Generating ideals and transforming lives: A contemporary case for the residential liberal arts college. Daedalus, the Journal of the American Academy of Arts and Sciences, 128, 173-194.

Johnson, B., \& Christensen, L. (2004). Educational research: Quantitative, qualitative, and mixed approaches (2nd edition). Boston, MA: Pearson Education Inc.

Johnsrud, L. K. (2002). Measuring the quality of faculty and administrative worklife: Implications for college and university campuses. Research in Higher Education, 43(3), 379-395

Klein, T. (2000). From classroom to learning community. About Campus, 5, 12-20.

Kuh, G. D., \& Hu, S. (2001). The effects of student-faculty interaction in the 1990's. The Review of Higher Education, 24(3), 309-332.

Kumar, R. (1999). Research methodology: A step by step guide for beginners. Thousand Oaks, CA: Sage.

Lester, S. (1999). An introduction to phenomenological research. Retrieved from web Address http://www.sld.demon.co.uk/resmethy.pdf.

Lindholm, J. A. (2003). Perceived organizational fit: nurturing minds, hearts, and personal ambitions of university faculty. The Review of Higher Education, 27(1), 125-149.

Lundberg, C. A. (2004). Quality and frequency of faculty-student interactions as predictors of learning: an analysis by student race/ethnicity. Journal of College Student Development, 45(5), 321-331.

Marchese, T. J. (1997). U.S. society and values. Electronic Journal of U.S. Information Agency, 2(4), 33-39.

Miles, M. B., \& Huberman, M. A. (1994). Qualitative data analysis. Thousand Oaks, CA: Sage Publications.

Pascaralla, E. T., \& Terenzini, P. T. (1991). How college affects students. San Francisco, CA: Jossey-Bass.

Pasque, P. A., \& Murphy, R. (2005). The intersections of living-learning programs and social identity as factors of academic achievement and intellectual engagement. Journal of College Student Development, 46(4), 429-441. 
Philpott, J. R, \& Strange, C. (2003). On the road to Cambridge: A case study of faculty and student affairs in collaboration. The Journal of Higher Education, 74(1), 7798.

Rubin, H. J., \& Rubin, I.S. (2005). Qualitative interviewing: The art of hearing data (2nd ed.). Thousand Oaks, CA: Sage Publications.

Ryan, M. B. (1992). Residential colleges: A legacy of living \& learning together. Change, 24, 12-19.

Sax, L. J., Bryant, A. N., \& Harper, C. E. (2005). The differential effects of studentfaculty interaction on college outcomes for women and men. Journal of College Student Development, 46(6), 642-659.

Shank, G. D. (2002). Qualitative research: A personal skills approach. Columbus, OH: Merrill Prentice Hall.

Terenzini, P. T., Pascarella, E. T., \& Blimling, G. S. (1999). Students' out-of-class experiences and their influence on learning and cognitive development: A literature review. Journal of College Student Development, 40(5), 610-623.

Vito, M. M. (2007). The impact of faculty-student interaction outside of the classroom on faculty satisfaction, engagement, and retention. Available From Proquest Dissertaions database (UMI \# 3273748).

Whitely, P.A (1994) Expectations, experiences and satisfaction by students, staff and faculty within residential colleges at the University of Miami. Dissertations fromProQuest. Paper \#3187. 
APPENDICES 
Appendix A

\section{EDF 6475 - Research Mini Project \\ Eric E. Arneson}

Research Question: "What is the self-perceived impact on faculty members of living in a residential college with undergraduate students?"

Interview Partners: 3 Current residential faculty members at a private research university in Southeast.

Process: Each faculty member will be interviewed one time for approximately 30-60 minutes regarding their experiences living with students.

Main Interview Questions:

- What drew you to become involved in a residential college?

- How did you feel you would benefit from the experience?

- What challenges did you anticipate facing?

- How do you describe your role as a faculty master or associate master to colleagues?

- How do you feel about the relationships you have formed with students?

- How do you feel about the relationships you have formed with other faculty or staff?

- What personal challenges has being in this position presented to you?

- What professional challenges has being in this position presented to you?

- How would you describe the rewards of being a master/associate master?

- What strategy would you employ to recruit fellow faculty members to this position?

- Why do you continue in the position?

- If you could change the position or responsibility what would you do differently?

- What else would you like to share about your experience of being a master/associate master that I have not asked you? 
Appendix B

\section{Modified Dissertation Interview Questions}

Research Questions: What are the self-perceived effects on residential faculty which result from outside of the classroom interaction with students?

What are the self-perceived effects on residential faculty satisfaction and persistence which result from outside of the classroom interaction with students?

Interview Partners: $7-10$ current and recent residential faculty members at a private research university in Southeast.

Process: Each faculty member will be interviewed one time for approximately 90 minutes regarding their experiences living with students.

Rationale: Rubin and Rubin (2005) outline the importance of questions revised from a smaller pilot study. They continued that it is important to have set and consistent follow up and probing questions to get optimal data from the interview partner.

Main Interview Questions:

- What drew you to become involved in a residential college?

1. Who first approached you in regards to this opportunity?

2. How did you feel your relationship with students would change?

3. What concerns crossed your mind?

- How did you feel you would benefit from the experience?

- What challenges did you anticipate facing?

1. What were your thoughts about the politics of the system?

2. How did current faculty masters describe issues?

- How do you describe your role as a faculty master or associate master to colleagues?

1. How were you supported or not?

2. Did this effect your tenure track or ability to research?

- How do you feel about the relationships you have formed with students?

1. How satisfied are you with the intensity and type of relationships you have formed with students as a result of this postion?

- How do you feel about the relationships you have formed with other faculty or staff?

- What personal challenges has being in this position presented to you?

1. How do your feel your personal time has been affected by this position?

2. How do you feel your privacy has been affected by this position? 
- What professional challenges has being in this position presented to you?

1. What has been the level of support by your department?

2. How has your research and/or publishing been effected?

- How would you describe the rewards of being a master/associate master?

- What strategy would you employ to recruit fellow faculty members to this position?

- Why do you continue in the position?

1. How do you feel your colleagues would answer this question?

2. What factors determine how long you continue in the position?

3. How has this position impacted how long you will persist at the institution as a whole?

- If you could change the position or responsibility what would you do differently?

- How would you describe your relationships with other faculty masters?

- How much has this experience enhanced or inhibited your teaching abilities?

- How has serving in this position affected your overall job satisfaction?

- What else would you like to share about your experience of being a master/associate master that I have not asked you? 
Appendix C

Statement of Informed Consent

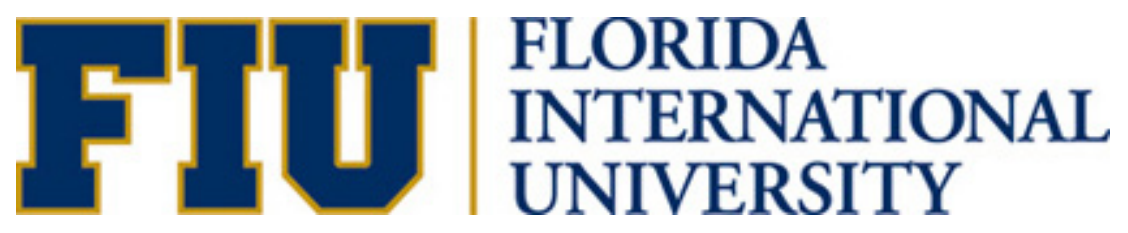

Letter of Informed Consent to Interviewees Participating in the Research Study

Title: The Self-perceived effects on residential faculty that result from outside of the classroom interactions with students

February 17, 2011

Dear Dr. XXX,

You are being asked to participate in a research study. The principal investigator of this study is Eric Arneson, a doctoral candidate in the Higher Education Program, Department of Educational and Leadership Policy Studies in the College of Education at FIU. The study will include approximately 15 current and/or former residential faculty members at your university. Your participation as an interviewee will require a total of approximately one hour of your time.

The purpose of the study is to learn how the role of the faculty master impacts you. I intend to discuss with you how this position and the associated out of class interactions with students have impacted your overall experience as a faculty member and as a person.

During the interview you will be asked questions about your experiences as a residential faculty member and how they have impacted you. I will ask you for any positive or challenging outcomes that you can identify as related to your experience. These questions will serve as a guide to the interview, but the format of the interview is open to reflect what you wish to share and you may elect to skip any questions that you do not want to answer. You are not required to participate in this study for any reason and you have the ability to end your participation at any time, for any reason. In addition, I will answer any questions you may have concerning this project. It is my hope that you may find that participating in this study provides a unique opportunity to reflect upon the ways that your experiences have impacted and will continue to guide you. The transcripts of each interview will be provided to you for your review prior to my analysis of data. I do not expect any harm to you by being in the study.

All of your answers are private and confidentiality will be maintained in the following ways: 
1) The recording and transcript of your interview will be identified by a special number (not your name).

2) I will ask that you develop a pseudonym that will be used in all written documentation or I will choose one for you if you prefer.

3) In addition, the recorded interviews will be deleted at the conclusion of the dissertation process.

If you would like more information about this research, please feel free to contact Dr. Roger Geertz Gonzalez, Major Professor, at (305) 348-3208. If you would like to talk to someone about your rights of being a subject in this study, you may contact Dr. Patricia Price, FIU Institutional Review Board chairperson at (305) 348-2618. If you have questions, need to contact me, or would like additional information, you may contact me at any time at (305) 987-4584 or via email at earneson@fiu.edu.

Your signature below indicates that you have read this document, that all of your questions have been answered, that you are aware of your rights, and that you would like to participate in this study.

Signature of Participant

Printed Name

Date

I have explained the research procedure, subject rights, and answered questions asked by the participant. I have offered her a copy of this consent form.

Signature of Researcher

Date 


\section{Appendix D}

\section{Residential Faculty Contract}

February 20, 2009

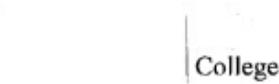

Thank you for agreeing to continue your service as Master of Mahoney Residential College for the 2009-2010 academic year. Your leadership in our residential colleges will enhance the development of the residentia', ife experience for our students.

Your appointment will begin on August 1,2009. It is a three-year appointment to be evaluated annually. Reappointment each year is based on performance as a resident faculty member and is subject to contin: al adherence to all University of Miami policies and procedures. Resident faculty members should be on campus during the Fall and Spring semesters each year and during staff training periods held in August and January.

As a residential college master, you will receive the following benefits:

- Accommodations in a designated apartment within the residential college for you and your immediate family members.' This will include local telephone service, utilities, basic cable, and meal plan.

- Two reserved parking spaces will be provided. You are responsible for the cost of a regular permit and the remainder of the cost for the reserved permit will be paid by the Department of Residence Halls.

- Local moving expenses to and from the residential college before and at the end of your term of service. To qualify for this benefit, moving arrangements must be made through the Director of Residence Halls.

- Routine maid service and additional service immediately following student programming events in the resident faculty apartment.

- Secretarial support for residential college business provided by the Department of Residence Halls. 
- Programming funds to cover student entertainment, community dinners and other educational, cultural and social costs incurred by you in the fulfillment of resident faculty duties and responsibilities.

Your responsibilities as a residential college master include:

- Providing intellectual and academic leadership for the residential college.

- Collaborating with residential college staff to design and coordinate weekly or monthly programs (depending on the nature of the program) for resident students. These programs should build sustainable links between the students' curricular and co-curricular experiences. Some programming should include collaboration with other campus offices, residential colleges, and units within the University community.

- Developing the appropriate assessment tools for the programs and conducting assessment of the programming to determine their efficacy in linking resident students' curricular and co-curricular experiences.

- Collaborating with residential college staff in implementing: student staff performance and development; Fall and Spring training; staff meeting agendas; Opening and Closing; and other Department of Residence Halls initiatives.

- Attending weekly senior staff meetings and staff meetings with the Associate Master, Residence Coordinator, and the Resident Assistants to plan programs and address building issues.

- Maintaining a significant visibility in the residential college. This includes attendance at College Council meetings and student programs; hosting faculty or community dinners; creating a discussion series and/or panel discussions; and participating in department events such as staff selection and end-of-the-year events.

- Contributing to and participating actively in the life of the residential college through both formal and informal interactions with students and staff.

- Attending monthly resident faculty meetings (Council of Masters).

- Submitting, with the Residence Coordinator and Associate Master, an annual report to the Senior Vice Provost. This report, due at the end of the Spring semester, should identify resident faculty activity, community involvement, academic programs \& events created within the college, assessment results of all programming, and recommendations for the next academic year.

- Serving informally as an advisor to students on academic and other University matters.

- Abiding by and role modeling all University policies and procedures.

- Facilitating student-initiated programming, using your expertise in dealing with both University and outside resources.

- Creating effective working relationships with the student staff and professional staff of the Department of Residence Halls, including resident assistants and academic fellows who live in the building, and the Associate Master. Masters have a significant responsibility to maintain continuous and open communication with the Director of the Residence Hall Office and with the Vice President for Student Affairs.

- Promoting the residential college system to the University as a whole.

An orientation session will be held for all resident faculty members in the later part of the Spring semester. You will be notified of the date, time, and location of this session. Also, attached is a list of important dates for the residential colleges to assist you in your planning. I hope and believe this will continue to be an enriching experience for you and look forward to working with you. 


\section{Important Residential College Dates for Resident Faculty}

2009-2010

- July 15 - August 1, 2009

- August 7, 2009
Move-in for resident faculty

Resident Assistant (RA) Training Begins

Resident faculty may participate in several training activities including the planning retreat which is typically held during the second week of August.

- August $22-23,2009$

Residential College Opening

- August 22- August 27

Orientation for HRC/SRC

In August, resident faculty participate in several residential college building activities designed to welcome students to campus.

- August 27- October 1 First six weeks of programming

Every Tuesday, each of the residential college staff meet for a staff meeting and resident faculty are expected to attend.

- October 2-4, 2009: Family Weekend

Bi-Weekly meetings are held with Resident Assistant Programming teams to plan upcoming residential college programs and speakers. Typically, each residential college faculty will host at least one to two programs in their apartments or in the lobbies with their Resident Assistant Programming Teams.

- November 7, 2009

- December 9, 2009

- December 19,2009

- January 9,2010

- January 11,2010

- $2^{\text {nd }}$ Week in February

- $3^{\text {rd }}$ Week in February

- March $18^{\text {th }}, 2010$

- Month of April 2010

- May 18,2010
Homecoming Weekend

Midnight Breakfast

Resident Assistants leave

Resident Assistants return

Residential Colleges Open for Spring semester

Sports-Fest Weekend

Resident Assistant Selection Weekend for 2010-2011

Resident Assistants for 2010-2011 are selected

Various meetings with new and returning staff for 2010-2011

Resident Assistants leave 
VITA

ERIC E. ARNESON

Education:

Florida International University

Ed.D Higher Education 2011

Miami, FL

Bowling Green State University

MA - College Student Personnel 1992

Bowling Green, $\mathrm{OH}$

University of Wisconsin at LaCrosse

BS - Political Science 1990

Lacrosse, WI.

Work Experience:

Director of Campus Life - Florida International University, Miami, Florida. July 2008 Present. Lead a department of 17 staff members overseeing student involvement for over 10,000 students.

- Directly supervise 7 staff and indirectly supervise 17 staff in day to day and developmental aspects of their jobs.

- Assume complete responsibility for $\$ 750,000$ office budget and oversee 19 total budget lines exceeding \$1.5million.

- Responsible for human resource decisions for department such as hiring, evaluating, and releasing staff.

- Directly advise the Black Student Union

- Engage the staff team to set yearly goals and maintain responsibility in achieving said goals.

- Represent the Division of Student Affairs in University Communicators Committee and as a liaison to Athletics and various other committees.

Assistant Dean of Students - Blue Sky University (pseudonym to protect confidentiality of participants in study). June 2007 - July 2008. Responsible for student conduct hearing and general student issues.

- Served as judicial hearing officer for students accused of policy violations.

- Administrated Emergency Dean program which provided after-hours response to student crisis.

- Appointed as the official liaison to Athletics and assumed reasonability for student conduct at major sporting events.

- Responsible for graduate student concerns and liaison with Graduate School. 
Associate Director of Residence Halls - Blue Sky University. August 2004 - June 2007. Served as senior residence life officer for residential community of 4,000 students.

- Directly Supervised 6 professional staff and indirectly supervised over 120 student employees.

- Served as emergency on-call professional staff for student crisis situations during and after work hours.

- Administrated budget in excess of $\$ 300,000$

- Assumed human resources responsibilities of hiring, training, and releasing staff.

- Liaison with live-in residential faculty regarding training all aspects of the residential college system.

- Represented department on many student affairs and university-wide committees and task forces.

Assistant Director of Residence Life - Western Illinois University, Macomb, Illinois.

June 2001 - July 2004. Oversaw all aspects of residence life program housing over 5,000 undergraduate, graduate, and students with families.

- Directly supervised 7 professional staff and indirectly supervised 22 graduate assistants and 140 resident assistants.

- Coordinated all human resource functions for graduate and professional staff.

- Liaison the Higher Education Department. Participated in CSP Days committee recruiting new graduate students in Higher Education.

- Responsible for multiple budgets.

Area Coordinator - University of Illinois at Urbana/Champaign. July 1996 - May 2001. Responsible for a residential area of 2,400 students. Supervised 6 professional staff, 4 graduate assistants and 44 resident assistants.

Residence Coordinator - Florida State University, Tallahassee Florida. July 1992 - May 1996. Responsible for residential area of 900 students while supervising a graduate assistant and 20 resident assistants.

Teaching Experience:

SLS 1501, July 2009 - Present. Florida International University. Teach freshman experience course designed to help student learn how to succeed in college.

College Student Personnel 675, Spring 2002. Western Illinoins University. Developed and instructed course for 20 graduate CSP students. Two credit course was focused on advising and supervising in the field of higher education. Responsible for all aspects of developing syllabus, choosing and ordering text books, and grading.

College Student Personnel 445, August 2001-May 2002. Western Illinois University. Had overall responsibility for course designed to supplement the leadership development of our resident assistants. Developed the curriculum, supervised course instructors, and taught three sections of course. 